\title{
Ultimate Compressive Strength Computational Modeling for Stiffened Plate Panels with Nonuniform Thickness
}

\author{
Hyun Ho Lee ${ }^{1}$. Jeom Kee Paik ${ }^{1,2,3}$ \\ Received: 8 May 2020 / Accepted: 1 August 2020 / Published online: 8 December 2020 \\ (C) The Author(s) 2020
}

\begin{abstract}
The aim of this paper is to develop computational models for the ultimate compressive strength analysis of stiffened plate panels with nonuniform thickness. Modeling welding-induced initial deformations and residual stresses was presented with the measured data. Three methods, i.e., ANSYS finite element method, ALPS/SPINE incremental Galerkin method, and ALPS/ULSAP analytical method, were employed together with existing test database obtained from a full-scale collapse testing of steel-stiffened plate structures. Sensitivity study was conducted with varying the difference in plate thickness to define a representative (equivalent) thickness for plate panels with nonuniform thickness. Guidelines are provided for structural modeling to compute the ultimate compressive strength of plate panels with variable thickness.
\end{abstract}

Keywords Ultimate compressive strength $\cdot$ Steel-stiffened plate structures $\cdot$ Nonuniform plate thickness $\cdot$ ANSYS finite element method $\cdot$ ALPS/SPINE incremental Galerkin method $\cdot$ ALPS/ULSAP analytical method

\section{Introduction}

Plate panels are used in naval, offshore, mechanical, aerospace, and civil engineering structures as primary strength parts of ships, ship-shaped offshore installations, fuselages, box-girder cranes, and bridges. They are usually designed

\section{Article Highlights}

- Computational models for the ultimate compressive strength analysis of stiffened plate panels with nonuniform thickness.

- Application of the three methods of ANSYS finite element method, ALPS/SPINE incremental Galerkin method, and ALPS/ULSAP analytical method.

- Validation of the computational models by a comparison with full-scale physical test.

- Guidelines for structural modelling to compute the ultimate compressive strength of stiffened plate panels with nonuniform thickness

Jeom Kee Paik

j.paik@ucl.ac.uk

1 Department of Naval Architecture and Ocean Engineering, Pusan National University, Busan, South Korea

2 The Korea Ship and Offshore Research Institute (Lloyd's Register Foundation Research Centre of Excellence), Pusan National University, Busan, South Korea

3 Department of Mechanical Engineering, University College London, London, UK and built with a uniform thickness over the plating, but nonuniform thickness is sometimes allocated to fulfill practical design requirements (Zenkour 2003; Lee et al. 2019; Tash and Neya 2020).

During the past several decades, the emphasis on structural design has moved from the allowable stress design to the limit state design because the latter approach makes possible a rigorously designed, yet economical, structure that directly takes into consideration the various relevant modes of failure (Paik 2018). Furthermore, limit states are key criteria within the framework of quantitative risk assessment and management which is now recognized to be the best way to effectively manage extreme conditions and accidents associated with the volatile, uncertain, complex, and ambiguous environments at every stage of design, construction, operation, and decommissioining of structures and infrastructure, and ultimately resolve such challenges (Paik 2020).

A limit state is formally defined by the description of a condition for which a particular structural member of an entire structure would fail to perform the function designated beforehand, and four types of limit states are relevant for structures, namely the servicebility limit state (SLS), the ultimate limit state (ULS), the fatigue limit state (FLS), and the accidental limit state (ALS) from the viewpoint of structural design (Paik 2018). This paper deals with the ultimate limit state of a steelstiffened plate structure under uniaxial compresive loads. 
A number of useful studies on the ultimate strength of plate panels for marine applications are found in the literature (Abdussamie et al. 2018; Benson et al. 2011; Gannon et al. 2013, 2016; Iijima et al. 2015; Jagite et al. 2019, 2020; Khan and Zhang 2011; Khedmati et al. 2014, 2016; Kim et al. 2009, 2015; Kumar et al. 2009; Lee and Paik 2020; Magoga and Flockhart 2014; Ozguc et al. 2006; Paik 2007; Paik et al. 2013; Rahbar-Ranji and Zarookoan 2015; Ringsberg et al. 2018; Shi and Gao 2020; Shi and Wang 2012; Zhang 2016; Wang et al. 2009). For plate panels of engineering structures with variable or nonuniform thickness, the structural responses should be characterized by taking into account the effects of variable thickness. Zenkour (2003) and Tash and Neya (2020) studied the bending behavior of transversely isotropic thick rectangular plates with variable thickness. de Faria and de Almeida (2003) and Le-Manh et al. (2017) studied buckling of composite plates with variable thickness. Zhang et al. (2018) studied buckling of egg-shaped shells with variable thickness under external pressure loads. However, no studies on the ultimate strength of isotropic plate panels with variable or nonuniform thickness are found in the literature.

The aim of the present paper is to contribute to developing computational models for the ultimate compressive strength analysis of steel-stiffened plate panels with nonuniform thickness. The paper is a sequel to the articles of Paik et al. (2020a, $\mathrm{b}, \mathrm{c}, \mathrm{d}, \mathrm{e})$ that dealt with full-scale progressive collapse testing on steel-stiffened plate structures under various circumstances such as low temperature or fires.

\section{A Target Stiffened Plate Panel}

A stiffened plate panel subjected to axial compressive loads is considered as shown in Figure 1. The panel is composed of three bays. The plating of outer two bays has a same thickness of $t$. However, the thickness for a half of the plating in the central bay is $t_{1}$ and $t_{2}$. The target plate panel with $t=t_{1}=t_{2}$ was fabricated with the framework of full-scale collapse tests (Paik 2020a, b, c, $\mathrm{d}$ and e), where the bottom plate panels of a containership carrying 1900 TEU were a reference.

The panel has four longitudinal stiffeners and two transverse frames with T-type as shown in Figure 2. The dimensions of longitudinal stiffeners in outer two bays are the same, but they are larger than from those in the central bay. This means that the outer two bays may not buckle until the central bay reaches the ultimate limit state. Table 1 presents the dimensions of the plate panel. The plate panel is fixed along the loaded edges (i.e., left and right ends), but the unloaded edges are simply supported, i.e., with the constraints of lateral deformation but free rotation. Also, the unloaded edges are allowed to move in-plane freely, implying that they may not keep straight as the plate panel deflects due to buckling.

The plate panel is made of high tensile steel with grade AH32. To define the mechanical properties of the material, the tensile coupon tests were conducted with specimens made in compliance with ASTM E8 (ASTM 2011), as shown in Figure 3. Figure 4 shows one of typical engineering stressengineering strain curves of the material obtained from tensile coupon tests with multiple specimens. Table 2 provides the mechanical properties of the AH32 steel.

\section{Modeling of Weld Fabrication-Induced Initial Imperfections of the Plate Panel}

The plate panel with $t=t_{1}=t_{2}=10 \mathrm{~mm}$ was fabricated in a shipyard in Busan, South Korea, which builds

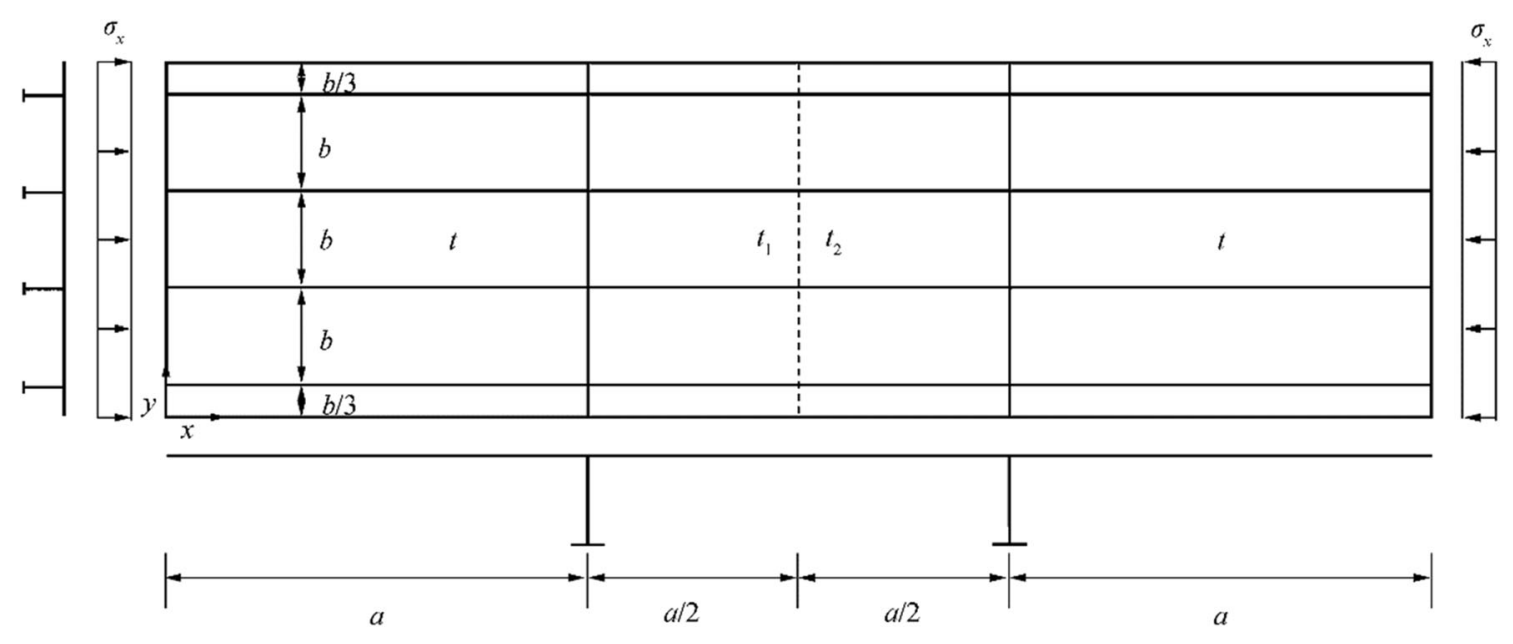

Figure 1 A stiffened plate panel 
Table 1 Dimensions of the target plate panel (unit: $\mathrm{mm}$ )

\begin{tabular}{|c|c|c|c|c|c|c|c|c|c|c|c|c|c|c|c|c|}
\hline \multirow[t]{2}{*}{$A$} & \multirow[t]{2}{*}{$b$} & \multicolumn{3}{|c|}{ Plate thickness } & \multicolumn{8}{|c|}{ Longitudinal stiffener } & \multicolumn{4}{|c|}{ Transverse frame } \\
\hline & & $t$ & $t_{1}$ & $t_{2}$ & Oute & & & & Cent & & & & $h_{w y}$ & $t_{w y}$ & $b_{f y}$ & $t_{f y}$ \\
\hline 3150 & 720 & 10 & Vary & Vary & $\begin{array}{l}h_{w x} \\
290\end{array}$ & $\begin{array}{l}t_{w x} \\
20\end{array}$ & $\begin{array}{l}b_{f x} \\
90\end{array}$ & $\begin{array}{l}t_{f x} \\
10\end{array}$ & $\begin{array}{l}h_{w x} \\
290\end{array}$ & $\begin{array}{l}t_{w x} \\
10\end{array}$ & $\begin{array}{l}b_{f x} \\
90\end{array}$ & $\begin{array}{l}t_{f x} \\
10\end{array}$ & 665 & 10 & 150 & 10 \\
\hline
\end{tabular}

small and medium-sized merchant and patrol ships. The technology of welding was exactly the same as used for fabrication of real ship structures. The flux-cored arc welding (FCAW) technique was applied in accordance with the welding procedure specification (WPS) requirements as indicated in Table 3. As per the welding requirements of DNVGL (2017), the penetration of welding was fully achieved with a leg length of $7 \mathrm{~mm}$ as shown in Figure 5. Figure 6 shows the plate panel after fabrication was completed in the shipyard.

\subsection{Modeling of the Plate Initial Deflection}

A 3D scanner was used to measure the welding-induced initial deformations for plating and support members. For details of the initial deformation measurements together with the thermal-elastic-plastic large deformation finite element method computations, Yi et al. (2020a) is referred to. Figure 7 presents the welding-induced initial deflection of plating in the plate length and breadth directions. It is seen that not only plating but also transverse frames were deflected by welding, where the relative maximum of the plate initial deflection was found
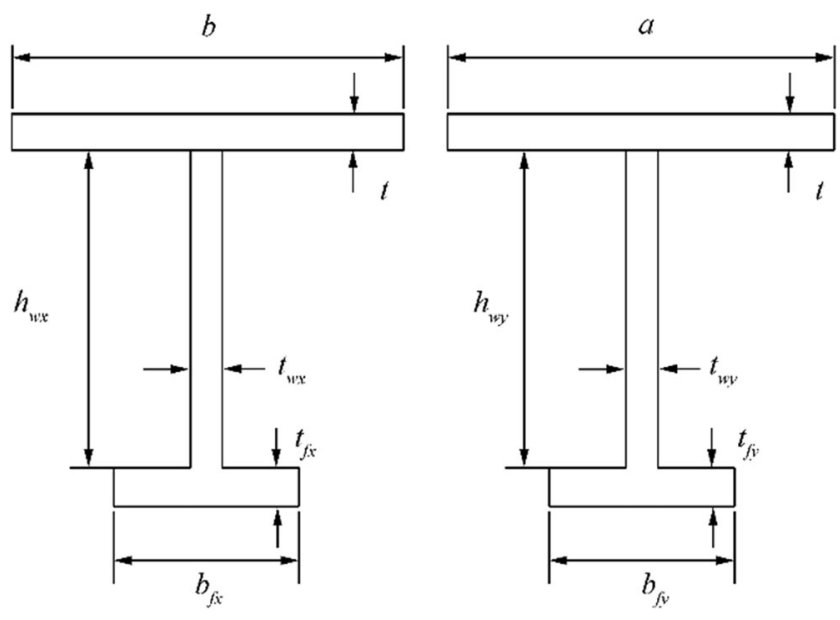

Figure 2 T-type support members in the $x$ and $y$ directions to be $1.73 \mathrm{~mm}$ based on the measured data. On the other hand, the maximum sideways deformation of longitudinal stiffeners was $0.42 \mathrm{~mm}$ which is $0.000133 a$. The web initial deflections for both longitudinal stiffeners and transverse frames were negligibly small (Figure 8).

The shape of the plate initial deflection is the so-called hungry horse's back type. In this case, the plate initial deflection of the central bay panel but excluding the unloaded side plates may be formulated by the following Fourier series equation (Paik 2018) where only a single half-wave between longitudinal stiffeners is allocated in the plate breadth direction.

$\frac{w_{0}}{w_{\text {omax }}}=\sum_{i=1}^{11} B_{o i 3} \sin \frac{i \pi x}{a} \sin \frac{3 \pi y}{B}$

where $w_{0}$ is the plate initial deflection function, $w_{0 \max }$ is the maximum plate initial deflection, $B=3 b$ is the breadth of the panel, and $B_{0 i 3}$ is the coefficient of the plate initial deflection.

The buckling mode of plating is defined as an integer satisfying the following equation.

$\frac{a}{b} \leq \sqrt{m(m+1)}$

where $m$ is the buckling half-wave number. With $a=$ $3150 \mathrm{~mm}$ and $b=720 \mathrm{~mm}, m=4$ is determined.

Equation (1) may be simplified with only the buckling component as follows:

$\frac{w_{0}}{w_{o \max }}=B_{o 43} \sin \frac{4 \pi x}{a} \sin \frac{3 \pi y}{B}$

where $B_{043}$ is the buckling component of the plate initial deflection function which may be taken as $B_{043}=0.0259$ (Paik 2018) as far as the hungry horse's back shape is applied.

\subsection{Modeling of the Residual Stresses}

As both longitudinal stiffeners and transverse frames are attached to the plating by welding, residual stresses must be 
Table 2 Mechanical properties of the AH32 steel obtained from the tensile coupon tests

\begin{tabular}{cccccc}
\hline Grade & $E(\mathrm{GPa})$ & $\sigma_{Y}(\mathrm{MPa})$ & $\sigma_{T}(\mathrm{MPa})$ & $\nu$ & $\varepsilon_{f}(\%)$ \\
\hline AH32 & 205.8 & 331 & 483 & 0.3 & 40.0 \\
\hline
\end{tabular}

$E$ is the elastic modulus, $\sigma_{Y}$ is the yield strength, $\sigma_{T}$ is the ultimate tensile strength, $\nu$ is the assumed Poisson's ratio, and $\varepsilon_{f}$ is the fracture strain

developed in the two directions as shown in Figure 9. Tensile residual stresses are developed in the heat-affected zone, and compressive residual stresses are developed in the middle of plating to fulfill the equilibrium condition between internal forces. The X-ray diffraction (XRD)

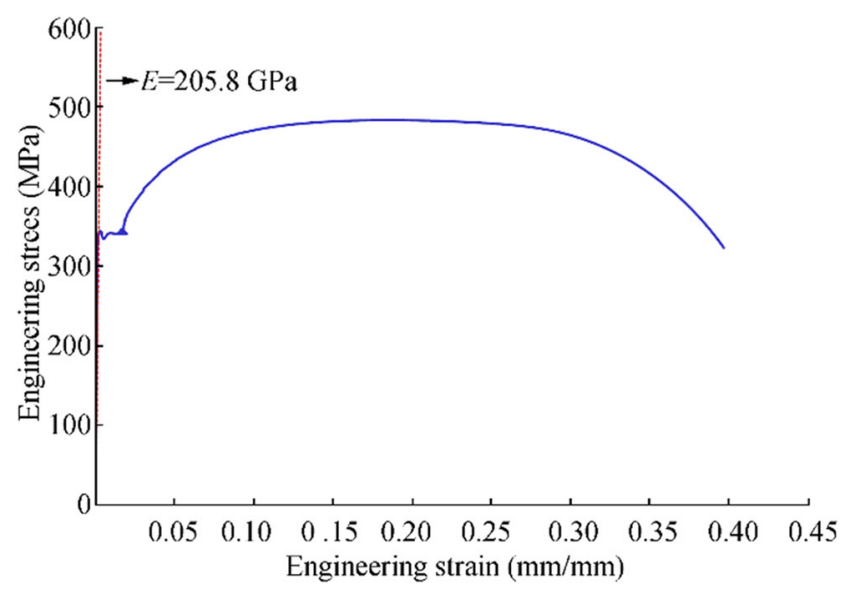

Figure 4 Engineering stress versus engineering strain curve of the AH32 steel

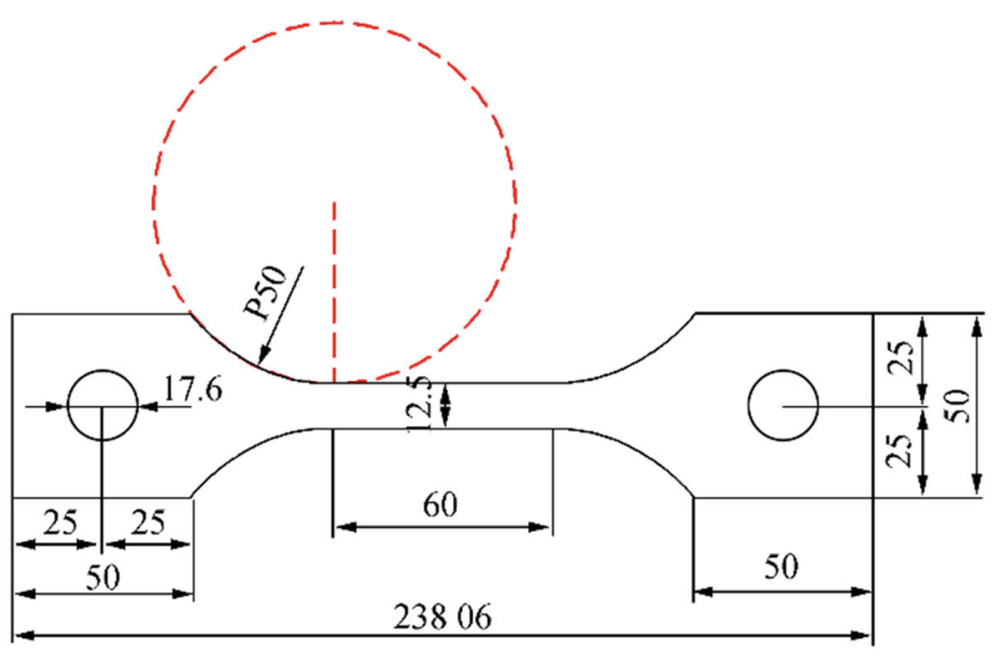

(a) Dimension of the tensile test specimen

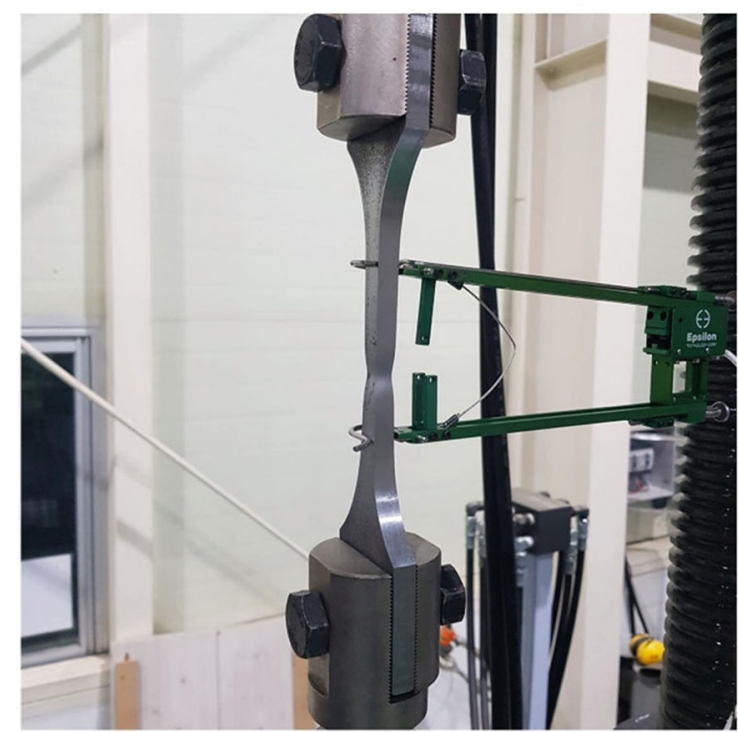

(b) Specimen with extensometer

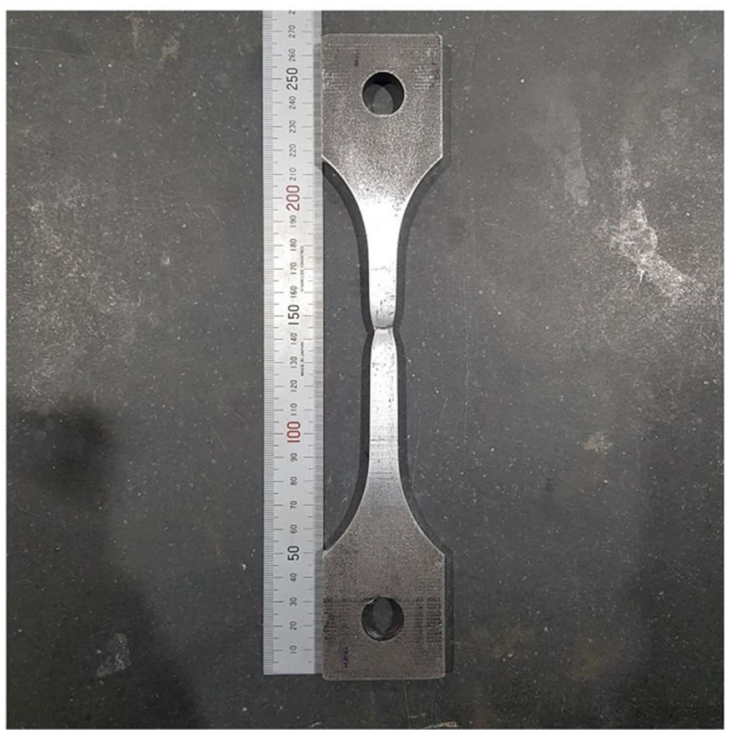

(c) Specimen after completing tensile test

Figure 3 Specimen of material used for the structure before and after tensile coupon tests 
Table 3 Welding parameters of the actual welding process and welding procedure specifications

\begin{tabular}{|c|c|c|c|c|c|}
\hline \multirow[t]{2}{*}{ Leg length, $L_{w}(\mathrm{~mm})$} & \multicolumn{5}{|c|}{ Welding parameter } \\
\hline & Weld condition & Current (A) & Voltage (V) & $\begin{array}{l}\text { Speed } \\
(\mathrm{cm} / \mathrm{min})\end{array}$ & Heat input $(\mathrm{kJ} / \mathrm{cm})$ \\
\hline \multirow[t]{2}{*}{7} & WPS & $225-275$ & $23-32$ & $24-34$ & $7-18$ \\
\hline & Real condition & 260 & 28 & 30 & 14.56 \\
\hline
\end{tabular}

method was used to measure welding-induced residual stresses in the plate panel. Details of the residual stress measurements together with the thermal elastic-plastic finite element method computations and the simple formula estimations are presented in Yi et al. (2020b). Figure 10 shows the comparison of welding-induced residual stresses between direct measurement, finite element method computations, and simple formula estimations.

The distribution of welding-induced residual stresses is often modeled as rectangular blocks of tensile and compressive residual stresses as shown in Figure 11. For welded steel plates, the welding-induced residual stresses may be estimated by the following procedure (Paik 2018).

From the equilibrium condition, the compressive residual stresses are obtained as follows:

$\sigma_{r c x}=\frac{2 b_{t}}{2 b_{t}-b} \sigma_{r t x}$

$\sigma_{r c y}=\frac{2 a_{t}}{2 a_{t}-a} \sigma_{r t y}$

where $b_{t}$ and $a_{t}$ are the breadth of tensile residual stress block in the plate breadth or length direction, respectively, $\sigma_{r t x}, \sigma_{r t y}$ are the magnitude of tensile residual stress block in the plate length or breadth direction, respectively, $\sigma_{r c x}, \sigma_{r c y}$ are the magnitude of compressive residual stress block in the plate length or breadth direction, respectively, $a$ is the plate length (spacing

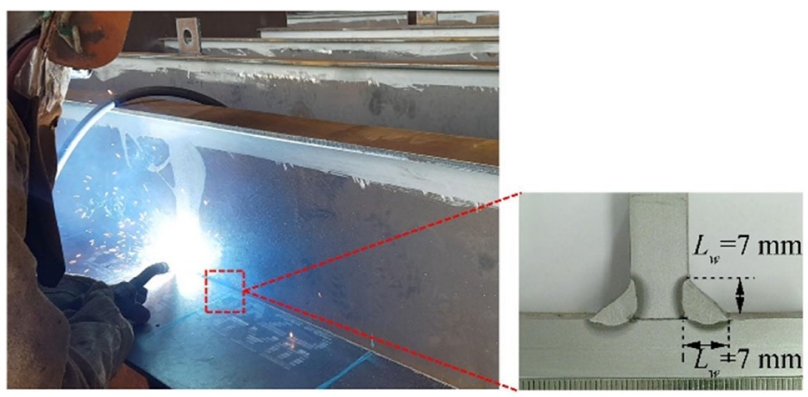

Figure 5 Full penetration of welds with a leg length of $7 \mathrm{~mm}$ between transverse frames), and $b$ is the plate breadth (spacing between longitudinal stiffeners). $\sigma_{r t x}$ and $\sigma_{r t y}$ are approximately equal to $\sigma_{Y}$ (material yield strength) for structural steels.

Equation (4) indicates that the compressive residual stresses can be estimated once the breadths of tensile residual stress blocks are defined. Empirical formulations of $b_{t}$ and $a_{t}$ were developed as a function of the weld leg length $L_{w}$ as follows (Paik 2018):

$b_{t}=c_{1} \times L_{w}+c_{2}$

where $c_{1}=-0.4562 \times \beta_{x}^{2}+4.1994 \times \beta_{x}+2.6354, c_{2}=1$. $1352 \times \beta_{x}^{2}-4.3185 \times \beta_{x}-11.1750$ and $\beta_{x}=\frac{b}{t} \sqrt{\frac{\sigma_{Y}}{E}}$.

$a_{t}=d_{1} \times L_{w}+d_{2}$

where $d_{1}=-0.0399 \times \beta_{y}^{2}+2.0087 \times \beta_{y}+8.7880$, $d_{2}=0.1042 \times \beta_{y}^{2}-4.8575 \times \beta_{y}-17.7950$ and $\beta_{y}=\frac{a}{t} \sqrt{\frac{\sigma_{Y}}{E}}$.

Using Eqs. (4)-(6), the magnitude of compressive residual stresses in the longitudinal and transverse directions can be estimated. The yield strength of the AH32 steel is $331 \mathrm{MPa}$, and thus, $\sigma_{Y}=\sigma_{r t x}=\sigma_{r t y}=331 \mathrm{MPa}$ is taken. Also, the leg length for the applied weld condition is $L_{w}=7 \mathrm{~mm}$. Therefore, the slenderness ratios are calculated as $\beta_{x}=2.88$ and $\beta_{y}=12.63$. Equations (5) and (6) provide the breadths of tensile residual stress blocks as follows:

$$
\begin{aligned}
c_{1} & =-0.4562 \times \beta_{x}^{2}+4.1994 \times \beta_{x}+2.6354 \\
& =-0.4562 \times 2.88^{2}+4.1994 \times 2.88+2.6354=10.9575 \\
c_{2} & =1.1352 \times \beta_{x}^{2}-4.3185 \times \beta_{x}-11.1750 \\
& =1.1352 \times 2.88^{2}-4.3185 \times 2.88-11.1750=-14.1797 \\
b_{t} & =c_{1} \times L_{w}+c_{2}=51.5655 \mathrm{~mm} \\
d_{1} & =-0.0399 \times \beta_{y}^{2}+2.0087 \times \beta_{y}+8.7880 \\
& =-0.0399 \times 12.63^{2}+2.0087 \times 12.63+8.7880=27.7960 \\
d_{2} & =0.1042 \times \beta_{y}^{2}-4.8575 \times \beta_{y}-17.7950 \\
& =0.1042 \times 12.63^{2}-4.8575 \times 12.63-17.7950=-95.7883 \\
a_{t} & =d_{1} \times L_{w}+d_{2}=70.9877 \mathrm{~mm}
\end{aligned}
$$



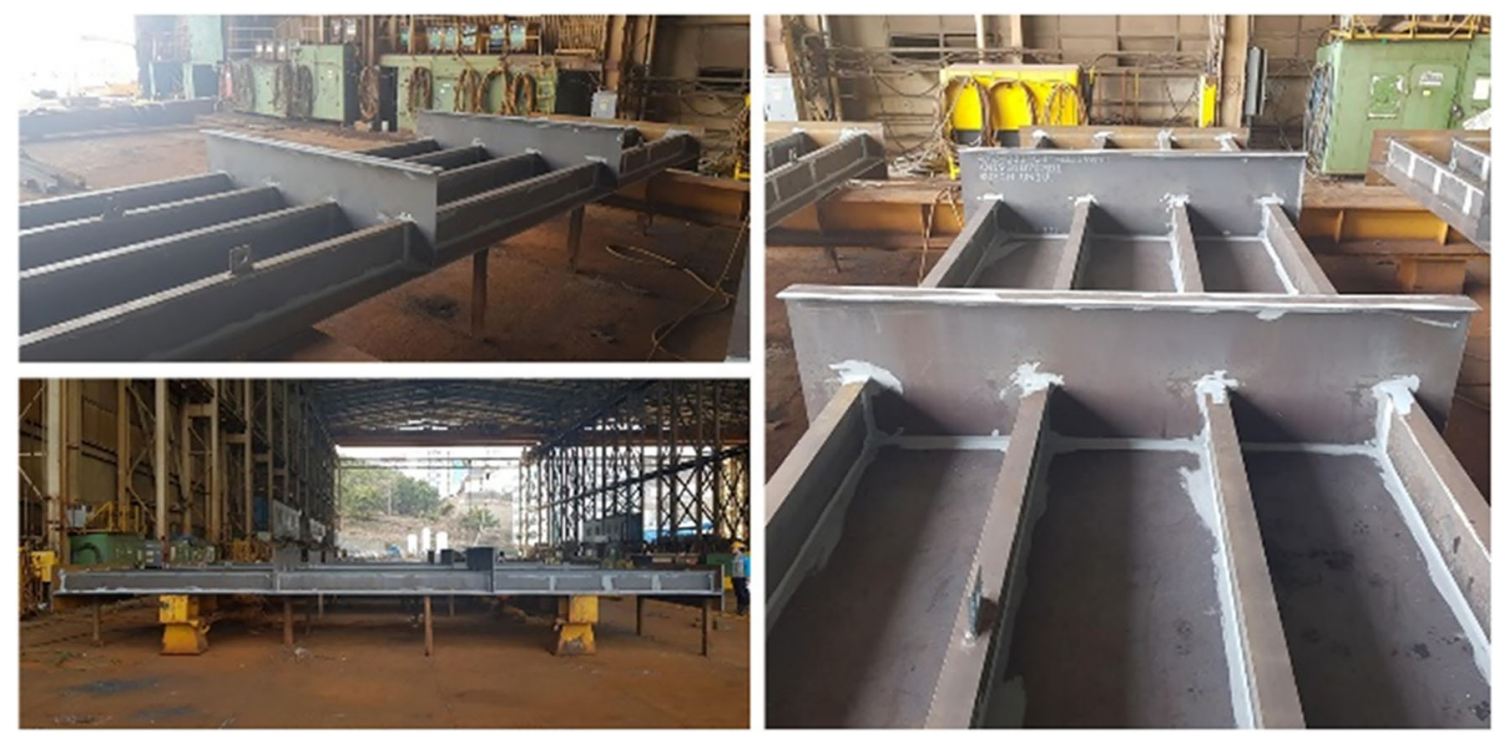

Figure 6 The plate panel after completing of fabrication in the shipyard

The compressive residual stresses in the longitudinal and transverse directions are estimated from Eq. (4) as follows:

$\sigma_{r c x}=-55.34 \mathrm{MPa}, \sigma_{r c y}=-14.92 \mathrm{MPa}$

Figure 10 presents the validity of the procedure to estimate the welding-induced residual stresses in the plate panel.

\section{Computational Models}

\subsection{ALPS/ULSAP (2020) Analytical Method}

The primary modes of overall failure for a stiffened plate structure are categorized into the following six types (Paik 2018):

- Mode I: overall collapse of plating and stiffeners as a unit

- Mode II: plate collapse without distinct failure of stiffeners

- Mode III: beam column-type collapse

- Mode IV: collapse by local web buckling of stiffener

- Mode V: collapse by lateral-torsional buckling (tripping) of stiffener

- Mode VI: gross yielding

Some collapse modes may in some cases interact and occur simultaneously, but it is typically considered that the collapse of the stiffened panels occurs at the lowest value among the various ultimate loads calculated when considering each of the abovementioned six collapse patterns separately. Details of the ULS computations for each of the six collapse modes are found in Paik (2018), and they have been implemented into the ALPS/ULSAP program (2020). This method accommodates the application of combined load components such as biaxial compression/tension, biaxial in-plane bending, edge shear, and lateral pressure loads. The effects of weldinginduced initial imperfections in the form of initial deformations and residual stresses are taken into account.

With ALPS/ULSAP, only the plate panel of the central bay which is assumed to be simply supported is taken as the extent of the analysis as shown in Figure 12. Also, only the buckling mode of the plate initial deflection is considered using Eq. (3). The measured values of the biaxial residual stresses are used but with the idealized distribution as shown in Figure 12. It is assumed that welding-induced residual stresses of longitudinal stiffeners are not considered. The column-type initial deflection of longitudinal stiffeners is assumed to be $0.0015 a$. The material follows the elastic-perfectly plastic model without considering strain-hardening effect.

A total of four cases with varying the thicknesses $t_{1}$ and $t_{2}$ are studied while the average value of them is kept constant at $t=\frac{t_{1}+t_{2}}{2}$ as indicated in Table 4 . For the ALPS/ULSAP analysis, the smaller value of the plate thickness, i.e., with $t_{\mathrm{eq}}=t_{2}$ when $t_{1} \geq t_{2}$ is used so that the ultimate strength is computed for the plate panel with a uniform thickness of $t_{\mathrm{eq}}=t_{2}$.

\subsection{ALPS/SPINE (2020) Incremental Galerkin Method}

The incremental Galerkin method developed by Paik et al. (2001) and Paik and Lee (2005) is a semianalytical method for computing the elastic-plastic large deflection behavior of steel or aluminum plates and stiffened panels up to their ultimate limit state (ULS). This method is designed to accommodate the geometric nonlinearity associated with buckling via an analytical procedure, whereas a numerical procedure accounts for 

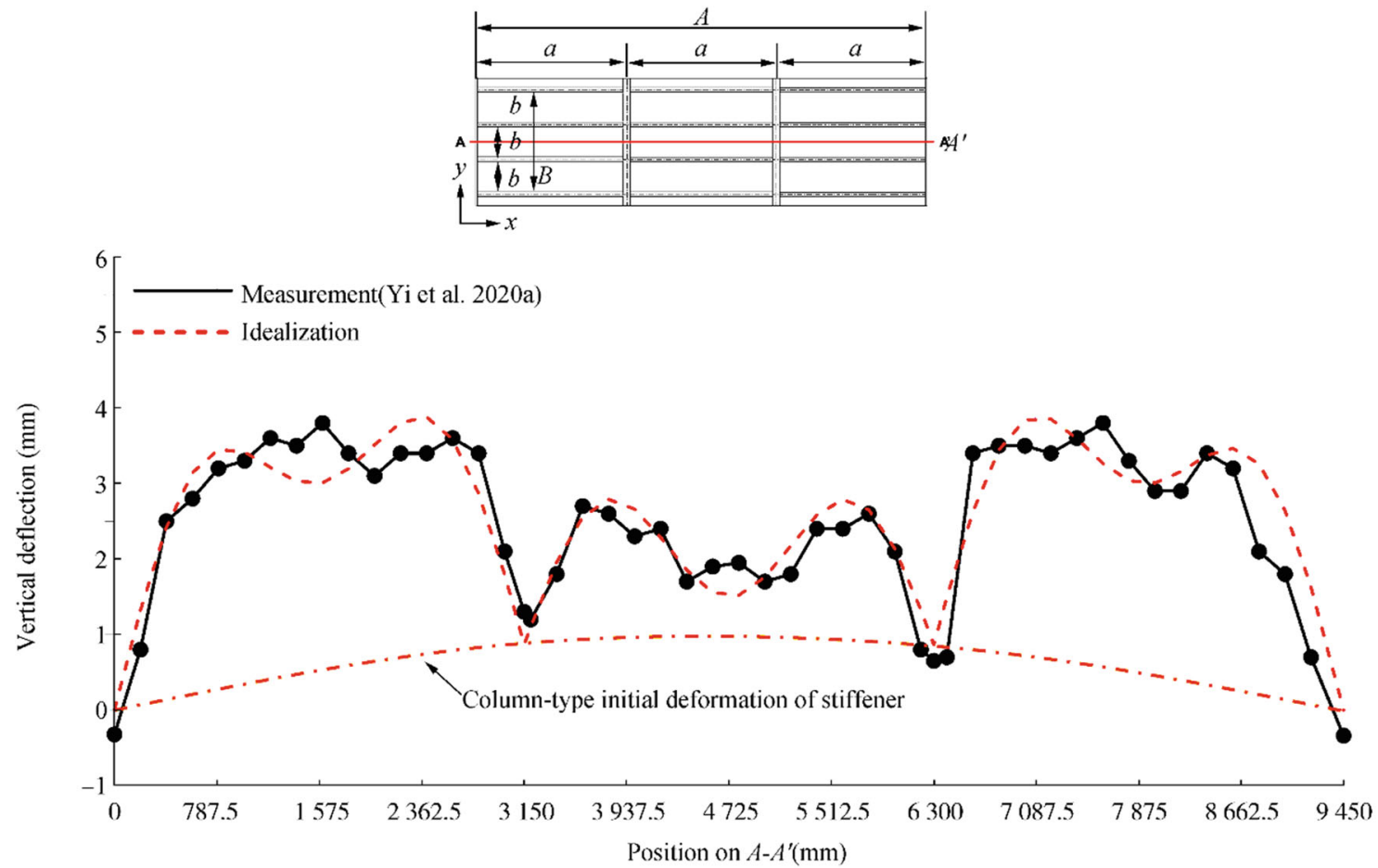

(a) Welding-induced initial deflection of plating in the plate length direction (along the A-A' section)

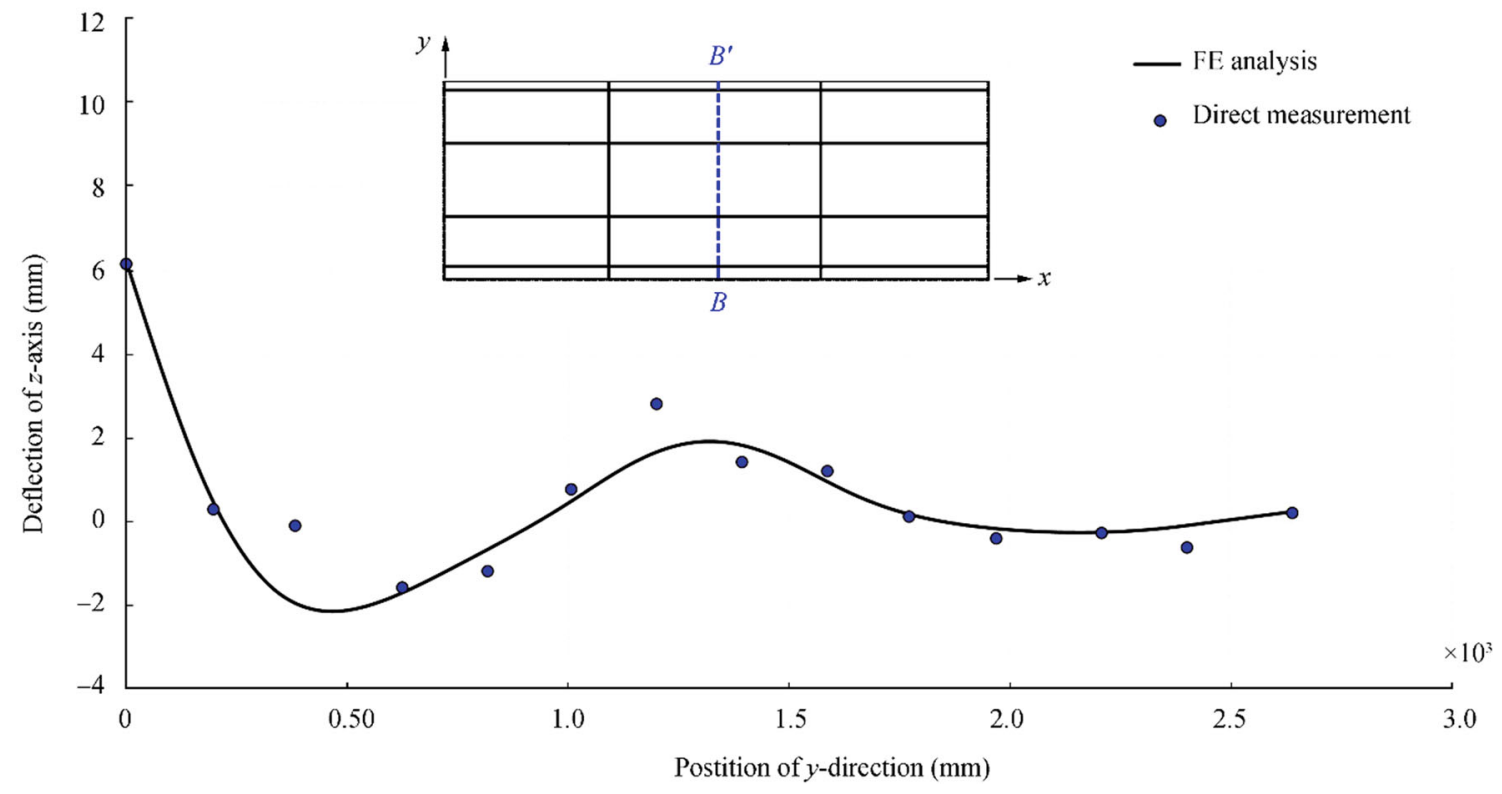

(b) Welding-induced initial deflection of plating in the plate breadth direction (along the B-B' section)

Figure 7 Comparison between direct measurements and numerical computations of plate initial deflections (Yi et al. 2020a)

the material nonlinearity associated with plasticity (Paik 2018). The method is unique in its use to analytically formulate the incremental forms of nonlinear governing differential equations for elastic large deflection plate theory. After solving these incremental governing differential equations using the Galerkin approach (Fletcher 1984), a set of easily solved linear first-order simultaneous equations for the unknowns is obtained, which facilitates a reduction in the computational effort.

It is normally difficult, but not impossible, to formulate the nonlinear governing differential equations to represent both geometric and material nonlinearities for plates and stiffened panels. A major source of difficulty is that an analytical treatment of plasticity with 


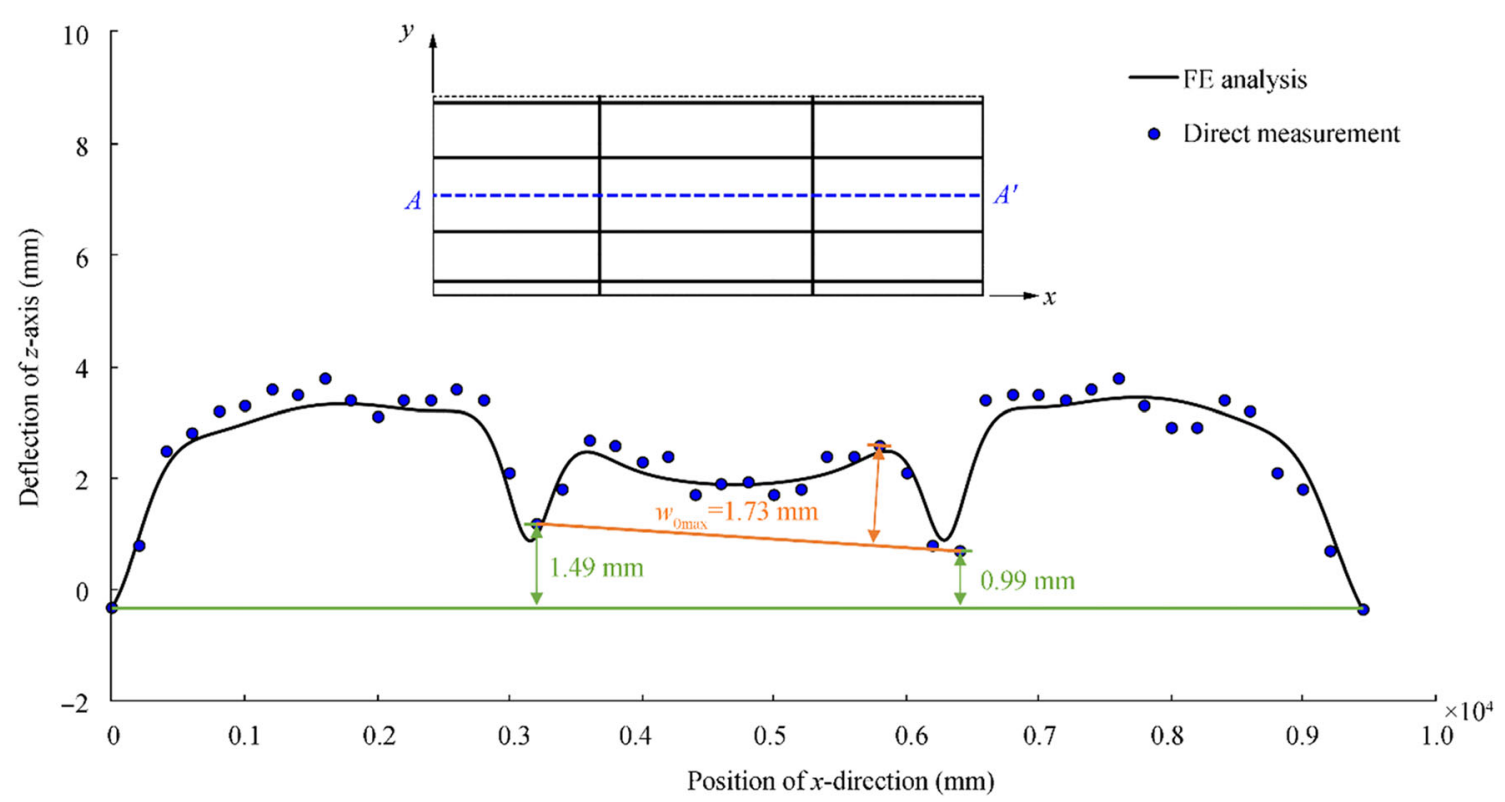

Figure 8 The maximum deflections of plating and transverse frames

increases in the applied loads is quite cumbersome. An easier alternative is to deal with the progress of the plasticity numerically. The benefits of this method are to provide excellent solution accuracy with great savings in computational effort and to handle in the analysis the combined loading for all potential load components, including biaxial compression or tension, biaxial in-plane bending, edge shear, and lateral pressure loads. The effects of initial imperfections in the form of initial deflection and welding-induced residual stresses are also considered. The present theory can be applied to both steel and aluminum plate panels. Details of the IGM theory and applied examples described in Paik (2018) have been implemented into the ALPS/SPINE program.

In the following, some of the more important basic hypotheses used to formulate the incremental Galerkin method for computation of the elastic-plastic large deflection behavior of plate and stiffened panels are described (Paik 2018).

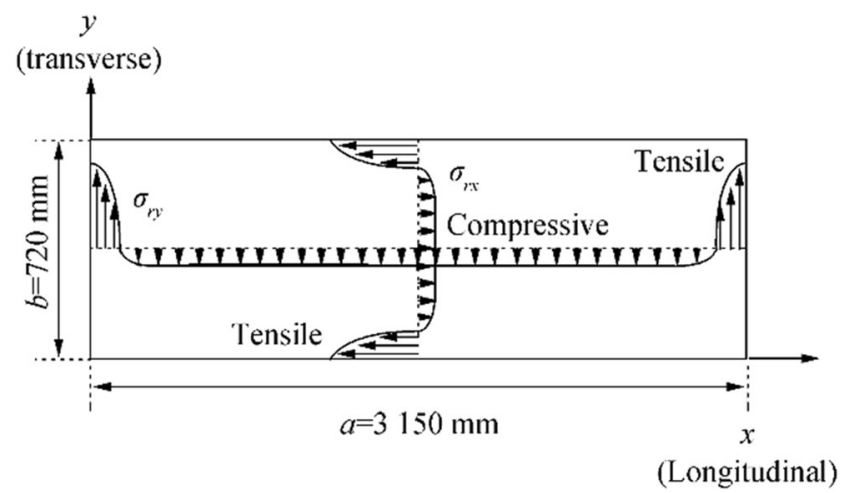

Figure 9 Distribution of welding-induced residual stresses in the two directions

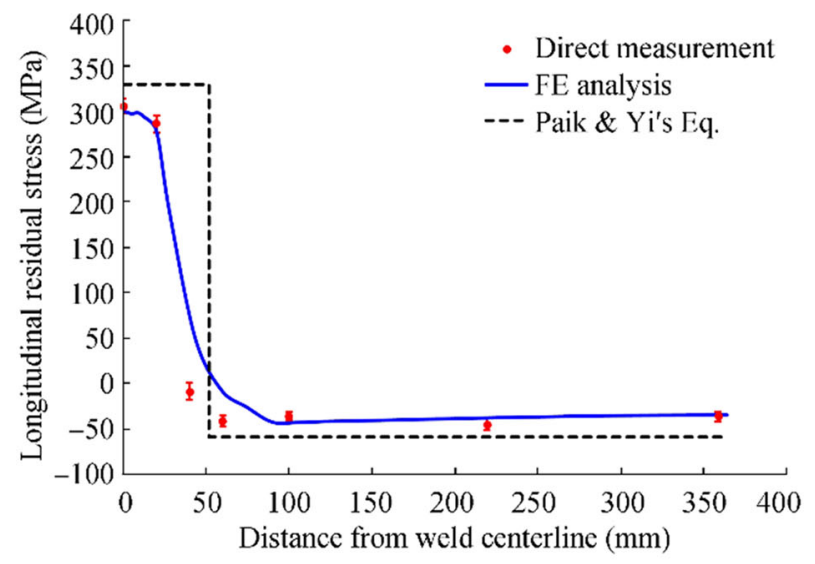

(a) Longitudinal stiffener direction

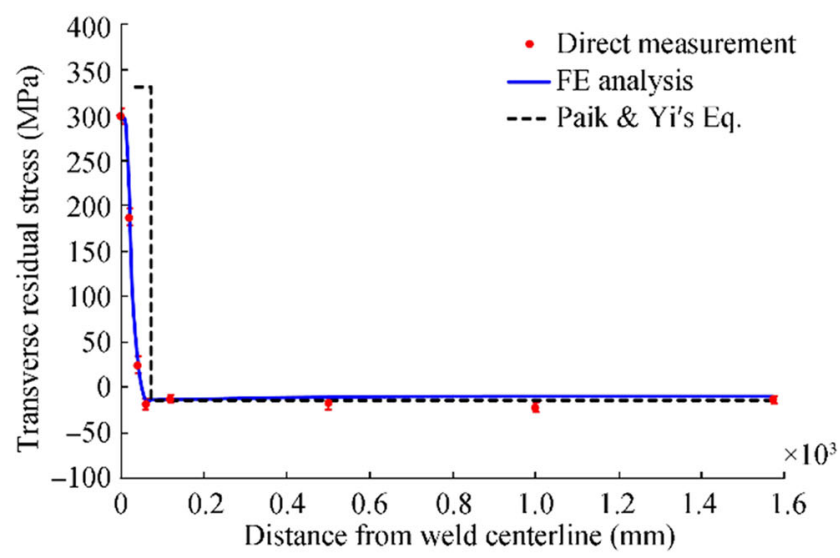

(b) Transverse frame direction

Figure 10 A comparison of welding-induced residual stresses between direct measurements, numerical predictions, and simple formula estimations 


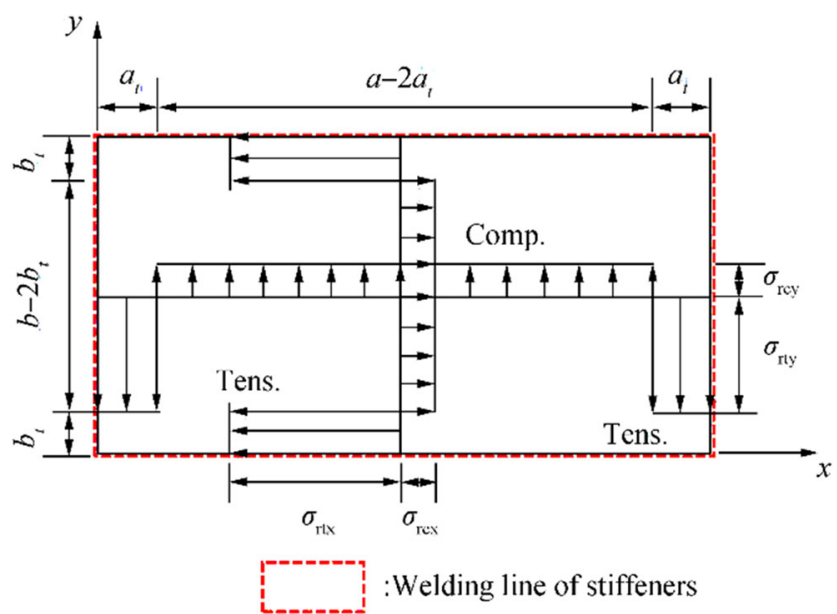

Figure 11 Idealization of the welding-induced residual stresses in a plate

The plate panel is made of isotropic homogeneous steel or aluminum alloys with a Young's modulus of $E$ and a Poisson's ratio of $v$. For a stiffened panel, Young's modulus of the plate part between stiffeners is the same as that of the stiffeners, but the yield stress of the plate part can differ from that of the stiffeners.

1) The length and breadth of the plate are $a$ and $b$, respectively, as shown in Figure 13a. The plate thickness is $t$.

2) The spacing of the stiffeners or the breadth of the plating between stiffeners can differ as shown in Figure 13b.

3) The material follows the elastic-perfectly plastic model without considering the strain-hardening effect.

4) The edge of the panel can be simply supported, clamped, or some combination of the two.

5) The panel is normally subjected to combined loads. Several potential load components act on the panel: biaxial compression or tension, edge shear, biaxial inplane bending moment, and lateral pressure loads, as shown in Figure 14.

6) The applied loads are increased incrementally.
Table 4 Variation of the plate thickness (unit: $\mathrm{mm}$ )

\begin{tabular}{lllrr}
\hline Case & \multicolumn{1}{l}{$t$} & \multicolumn{1}{l}{$t_{1}$} & \multicolumn{1}{c}{$t_{2}$} & $t_{\mathrm{eq}}=t_{2}$ \\
\hline 1 & 10.0 & 10.0 & 10.0 & 10.0 \\
2 & 10.0 & 10.5 & 9.5 & 9.5 \\
3 & 10.0 & 11.0 & 9.0 & 9.0 \\
4 & 10.0 & 11.5 & 8.5 & 8.5 \\
\hline
\end{tabular}

7) The shape of the initial deflection in the plate panel is normally complex, but it can be expressed with a Fourier series function. For a stiffened panel, the plate part between stiffeners may have the same set of local plate initial deflections, whereas the stiffeners may have a different set of global column-type initial deflections.

8) Due to the welding along the panel edges and at the intersections between the lower part of the stiffener web and parent plate, the panel has welding-induced residual stresses. These can develop in the plate part in both $x$ and $y$ directions, as welding is normally carried out in these two directions. As shown in Figure 15, the distribution of welding-induced residual stresses for the plate part between stiffeners is idealized to be composed of two stress blocks, i.e., compressive and tensile residual stress blocks. It is assumed that the stiffener webs have uniform compressive residual stresses "equivalent" to that shown in Figure 14.

9) For evaluation of the plasticity, it is assumed that the panel is composed of a number of membrane fibers in the $x$ and $y$ directions. Each membrane fiber is considered to have a number of layers in the $z$ direction, as shown in Figure 15.

10) It is recognized that the strength of welded aluminum alloys in the softened zone may be recovered by natural aging over a period of time, but the ultimate strength of welded aluminum alloy panels may be reduced by softening phenomenon in the heat-

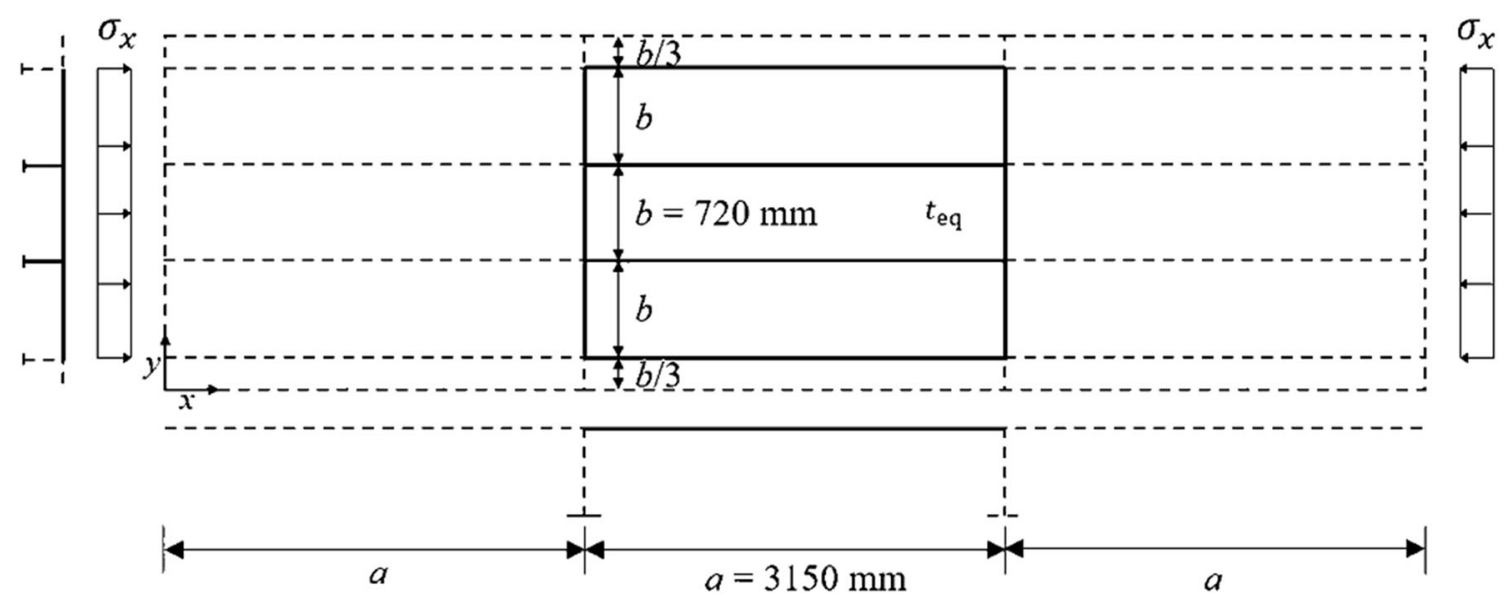

Figure 12 Extent of the ALPS/ULSAP and ALPS/SPINE analyses 


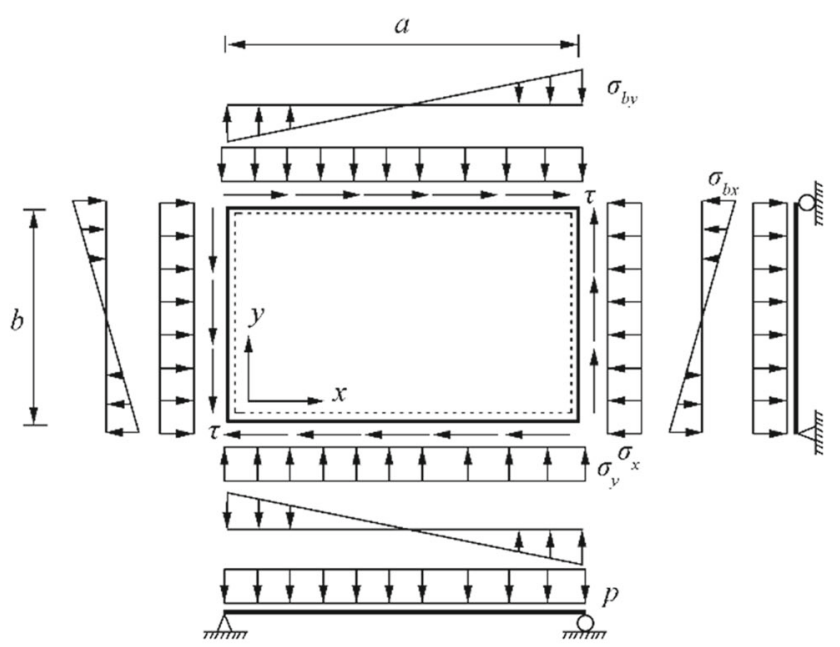

(a) Plate

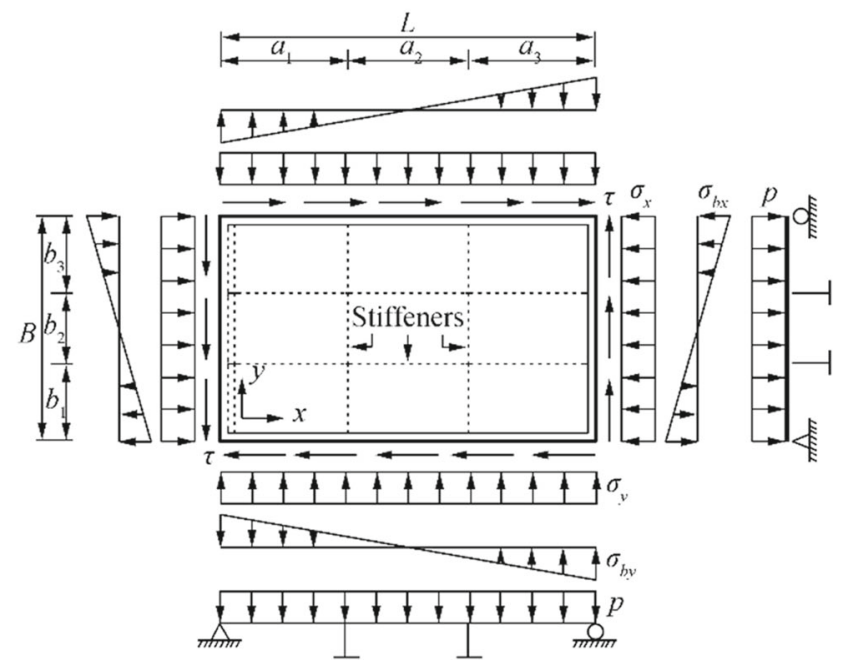

(b) Stiffened panel

Figure 13 Application of combined in-plane and out-of-plane loads

affected zone as far as the material strength is not recovered. The effect of softening is accounted for using the technique noted in item 9 above.

The extent of the ALPS/SPINE analysis was the same as that of the ALPS/ULSAP analysis as shown in Figure 12. The plate initial deflection was assumed as follows:

$\frac{w_{0}}{w_{o \max }}=\sin \frac{\pi x}{a} \sin \frac{3 \pi y}{B}+B_{o 43} \sin \frac{4 \pi x}{a} \sin \frac{3 \pi y}{B}$

Furthermore, the added plate deflection under applied loads was assumed to follow the equation.

$w=\sum_{i=1}^{9} A_{i 3} \sin \frac{i \pi x}{a} \sin \frac{3 \pi y}{B}$

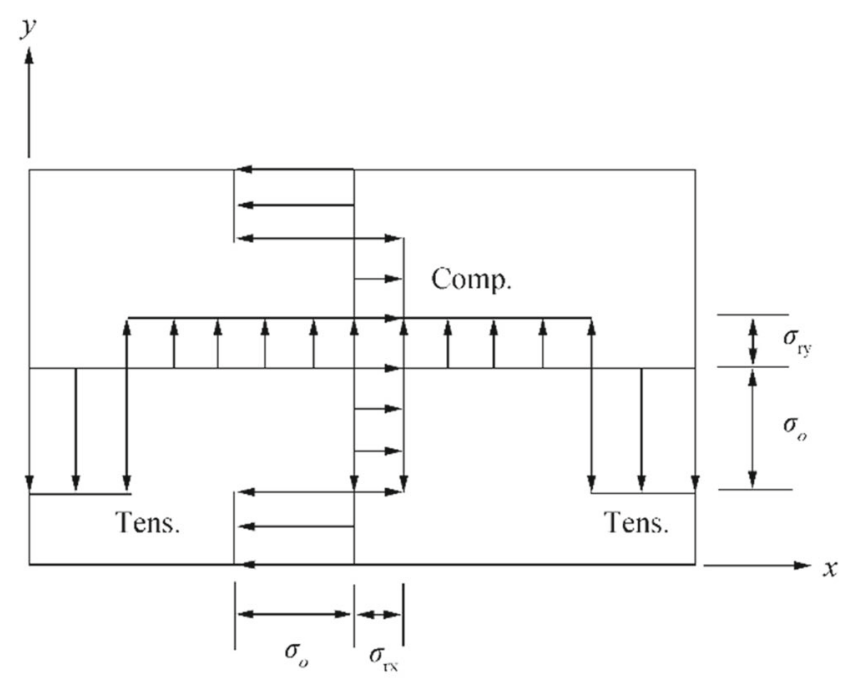

(a) Plating

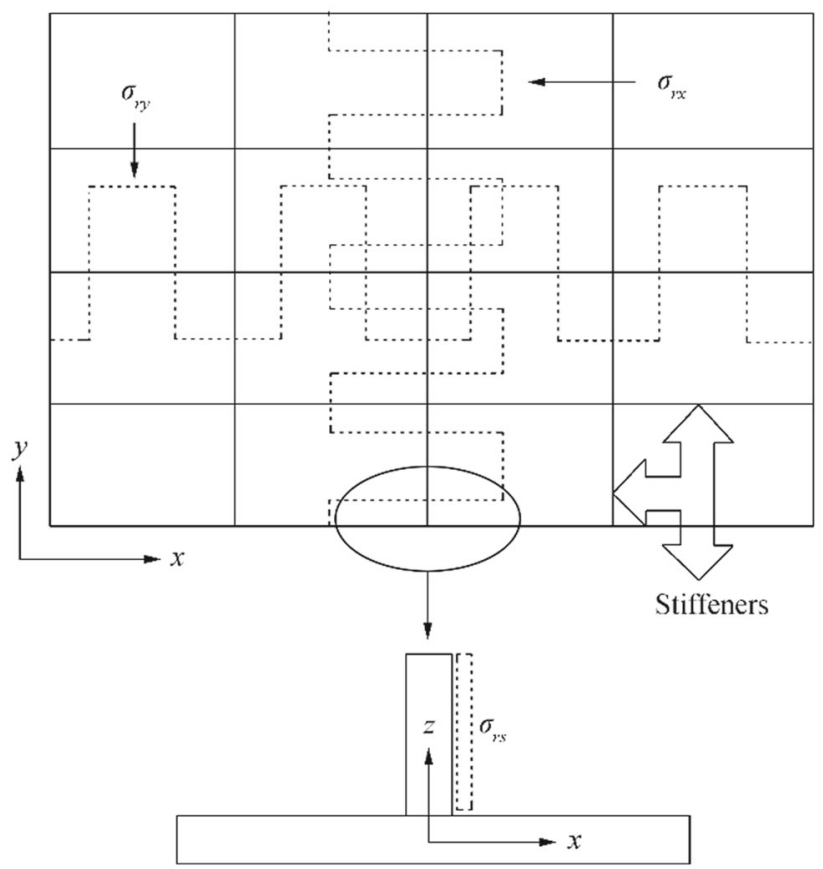

(b) Stiffeners

Figure 14 Idealized welding-induced residual stress distributions

where $w$ is the added plate deflection and $A_{i 3}$ is the amplitude of added deflection components.

Similar to the ALPS/ULSAP model, the measured values of the biaxial residual stresses were used but with the idealized distribution as shown in Figure 12. It was assumed that welding-induced residual stresses of longitudinal stiffeners were not considered. The column-type initial deflection of longitudinal stiffeners was assumed to be $0.0015 a$. Again, a total of four cases including one case with uniform plate thickness were studied as indicated Table 4 . The smaller value of the plate thickness, i.e., with $t_{\mathrm{eq}}=t_{2}$ when $t_{1} \geq t_{2}$ was applied for the ALPS/SPINE analysis. 


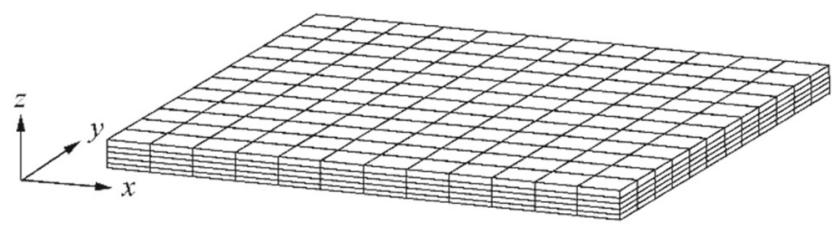

(a) Plate

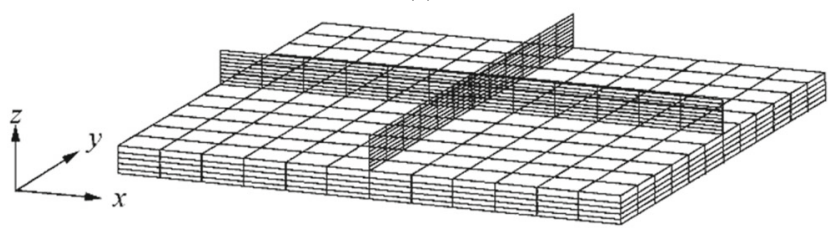

(b) Stiffened panel (geometric nonlinearity is analytically handled)

Figure 15 Example subdivision of mesh regions used for treatment of plasticity

\subsection{ANSYS (2019) Finite Element Method}

The entire structure was taken as the extent of the analysis as shown in Figure 16. Only plate elements (with an aspect ratio of unity if possible) were used to model not only plating but also support members including both webs and flanges. The mesh size was taken as $b / 10$ for plating. Two elements (with one element at each side of T-bar) were used for the flange of longitudinal stiffener, and four elements (with two elements at each side of T-bar) were used for the flange of transverse frame.

The plate initial deflection was assumed with only the buckling mode of Eq. (3). The measured initial deflection of transverse frames shown in Figure 8 was directly considered. The measured residual stresses were included in the modeling. The maximum sideway deformation of longitudinal stiffeners was applied, and the web initial deflections of both longitudinal stiffeners and transverse frames were neglected. In contrast to ALPS/ULSAP and ALPS/SPINE analyses, the actual plate thicknesses of $t_{1}$ and $t_{2}$ were directly included in the ANSYS modeling, while a total of four cases were studied as indicated in Table 4. The elastic-perfectly plastic material model was applied for the ANSYS analysis. Figure 17 shows the finite element model of the tested structure. Figure 18 shows the boundary condition applied for the ANSYS finite element analysis which was the same as for the tested structure.

\section{Computed Results and Discussion}

Figure 19 shows the applied compressive load versus axial shortening curves of the plate panel with $t=t_{1}=$ $t_{2}=10 \mathrm{~mm}$, where unloaded edges are allowed to move in-plane freely without keeping straight. To investigate the effect of the straight edge condition at unloaded edges, a comparison was made in terms of the inplane displacement as shown in Figure 20. It is obvious from Figure 20 that the in-plane displacement was allowed for the nonstraight condition at unloaded edges, but the difference is very small and can be neglected. In fact, the computed results of the ANSYS finite element method in Figure 19 show identical despite the edge straight condition. Figure 21 shows the deformed shape of the plate panel with $t=t_{1}=t_{2}=10 \mathrm{~mm}$ at the ultimate limit state obtained from the ANSYS finite element method analysis. The deformed shape of the plate panel observed by the ANSYS analysis is comparable with that by the experiment as shown in Figure 22 where the panel reached the ultimate limit state by collapse mode V (tripping of the stiffeners), although the ANSYS computations did not show a clear tripping failure.

To examine the effects of nonuniform thickness on the plate ultimate compressive strength, a series analyses were conducted with varying the plate thickness as indicated in Table 4, where the average value of the plate thickness is the same as $10 \mathrm{~mm}$. Figure 23 shows the ultimate compressive strength behavior of the plate panel obtained from the ANSYS finite element method analysis with varying the plate thickness. Figure 24 shows the ALPS/SPINE analysis results in terms of added deflection components until the ultimate strength is reached with varying the plate thickness. It is interesting to see that the global pattern of the plate deflection increases in the beginning as the axial compressive loads are increased, but it eventually decreases (and disappears) as the plate buckles so that the buckling mode becomes dominant.

The ALPS/ULSAP predictions were also carried out, and they showed that the panels of the four cases all reached the ultimate limit state by the tripping failure (collapse mode V). Table 5 summarizes the ultimate strength computations together with the experimental result. Figure 25 compares the ultimate compressive strengths obtained from the case studies. The ultimate strength obtained by ANSYS is greater than the experiment by $7.2 \%$ for case 1 with $t=t_{1}=t_{2}=10 \mathrm{~mm}$. It is found that the ANSYS ultimate compressive strength computations of the plate panel with nonuniform thickness decrease as the lower plate thickness $t_{2}$ decreases. For case 4 with a thickness difference of $t_{1}-t_{2}=3 \mathrm{~mm}$, the reduction ratio of the ANSYS ultimate strength computation is $16.1 \%$.

On the other hand, the analytical solutions for case 1 are smaller than the experiment by $3.2 \%$ for the ALPS/ULSAP analysis and $6.6 \%$ for the ALPS/SPINE analysis. By 


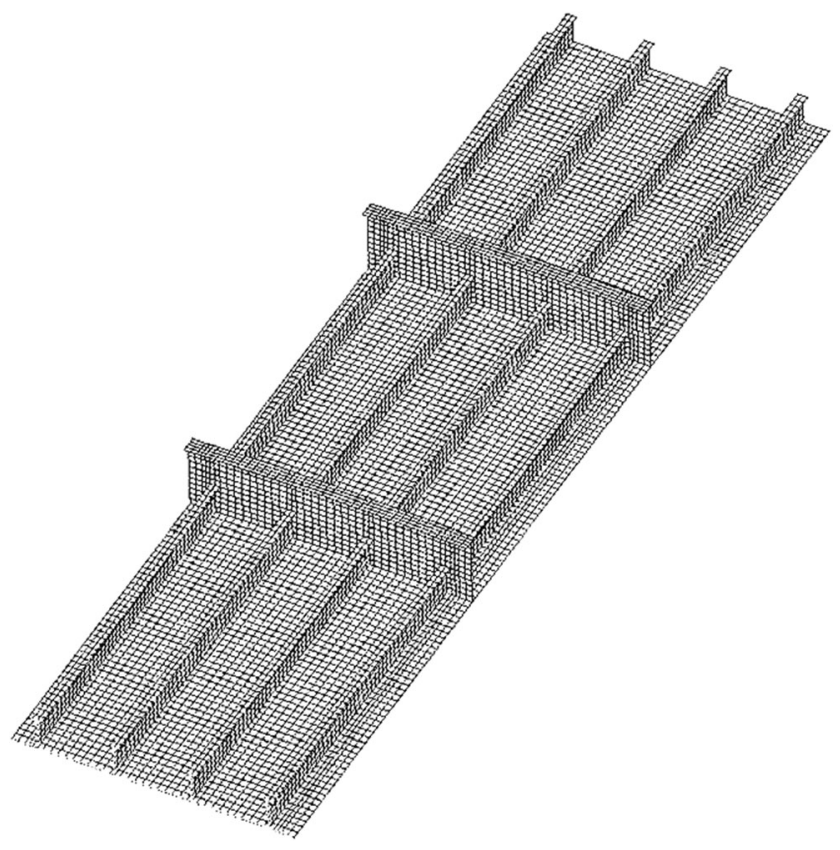

Figure 16 Extent of the ANSYS finite element method analysis

comparing with case 1 and case 4 , the reduction rate of the ultimate strength is $3.3 \%$ for the ALPS/ULSAP analysis and $6.3 \%$ for the ALPS/SPINE analysis. It is obvious that the analytical solution of the panel ultimate strength decreases as the lower thickness decreases, but the reduction rate is much small in contrast to the ANSYS computations.

Based on the case studies, it is considered that the average thickness, i.e., $t_{\mathrm{eq}}=\frac{t_{1}+t_{2}}{2}$ can approximately be used for the analytical approaches (e.g., ALPS/ULSAP or ALPS/SPINE) of plate panels with nonuniform thickness. The nonlinear finite element method can of course account for actual thicknesses directly.

\section{Concluding Remarks}

The aim of the paper was to investigate the effects of nonuniform thickness on the ultimate compressive strength of plate
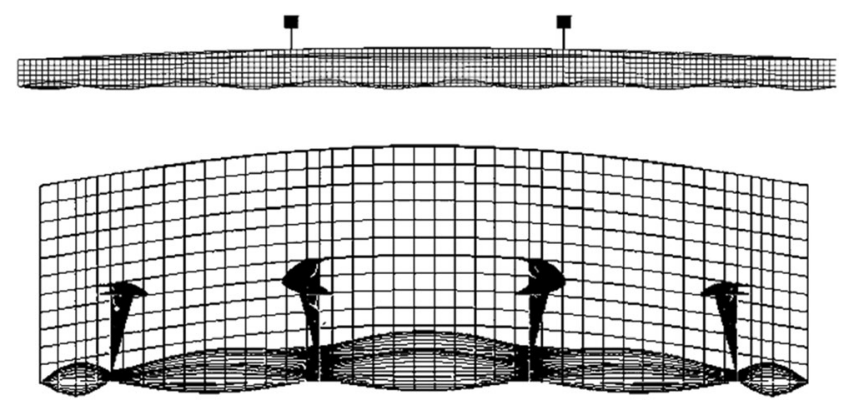

Figure 17 Modeling of initial deformations in the plate and support members

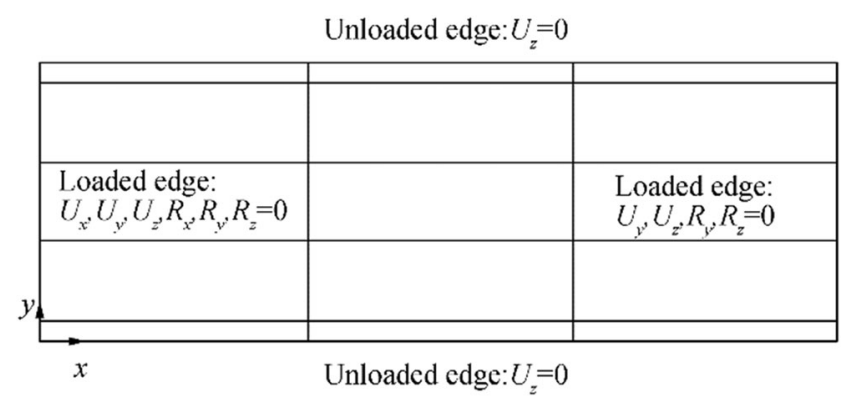

Figure 18 Boundary condition applied for the ANSYS finite element method analysis

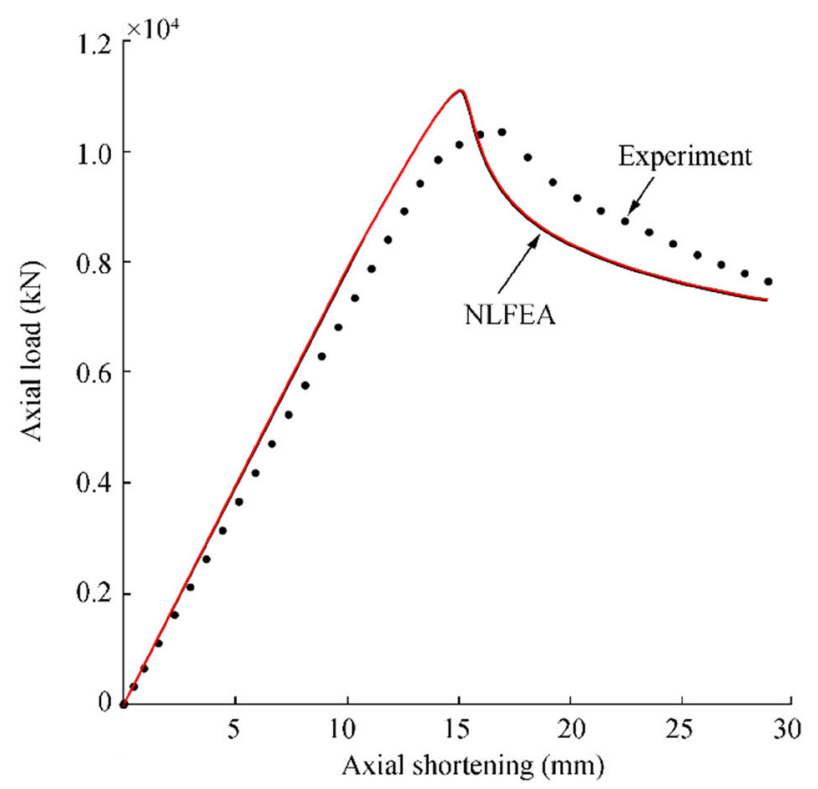

(a) Axial load-axial shortening curve

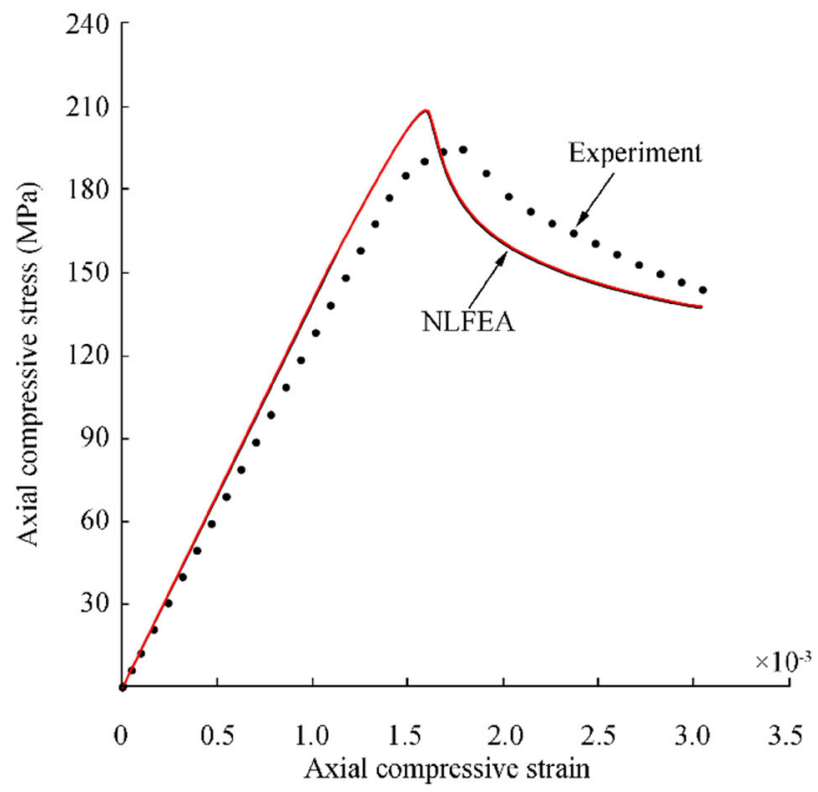

(b) Axial compressive stress-axial compressive strain curve

Figure 19 Comparison of the ultimate compressive strength behavior of the plate panel between the experiment and ANSYS finite element method analysis 

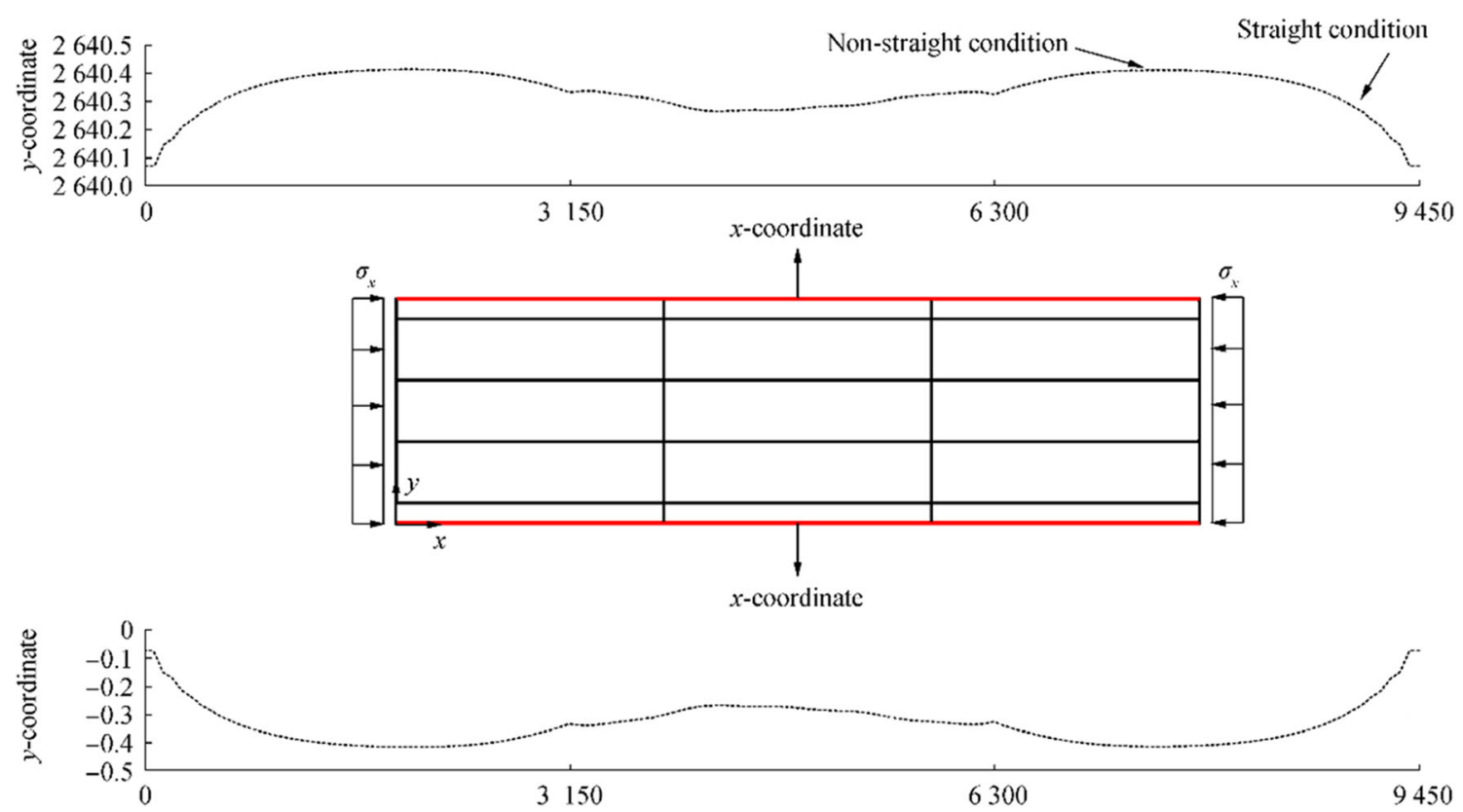

Figure 20 Effects of the straight condition at unloaded edges in terms of the in-plane displacement

panels so that a recommended practice for defining a representative (equivalent) plate thickness was developed. Case studies were conducted by varying the plate thickness. Based on the studies, the following conclusions can be drawn.

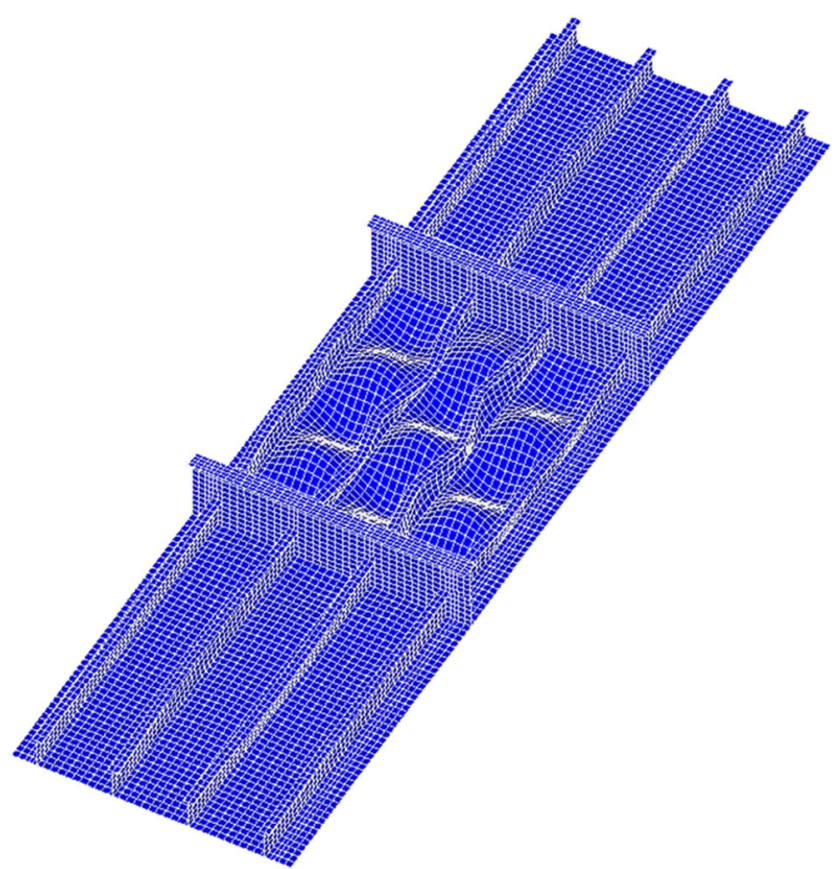

Figure 21 Deformed shape of the plate panel at the ultimate limit state obtained from the ANSYS finite element method analysis (with an amplification factor of 20)
1) The modeling techniques of welding-induced initial deflections and residual stresses in plate panels were presented in association with the measure data.

2) The ANSYS ultimate compressive strength computation for the plate panel with a uniform thickness of $10 \mathrm{~mm}$ (case 1) was greater than the experiment by $7.2 \%$.

3) The ALPS/ULSAP or ALPS/SPINE ultimate compressive strength solutions for the plate panel of case 1 were smaller than the experiment by $3.2 \%$ and $6.6 \%$, respectively.

4) According to the ANSYS computations, the ultimate compressive strength of plate panels with nonuniform thickness decreases as the lower thickness decreases or the thickness difference increases as far as the average thickness is kept constant.

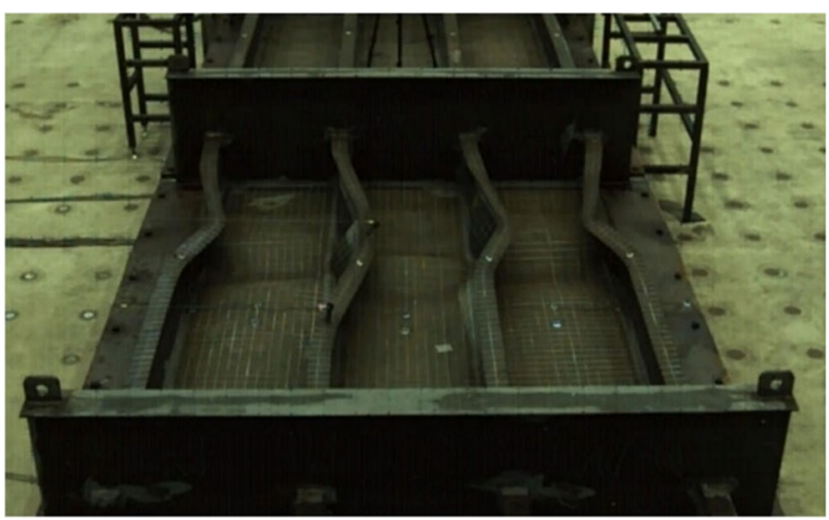

Figure 22 Deformed shape of the plate panel at the ultimate limit state observed from the experiment (Paik et al. 2020a) 


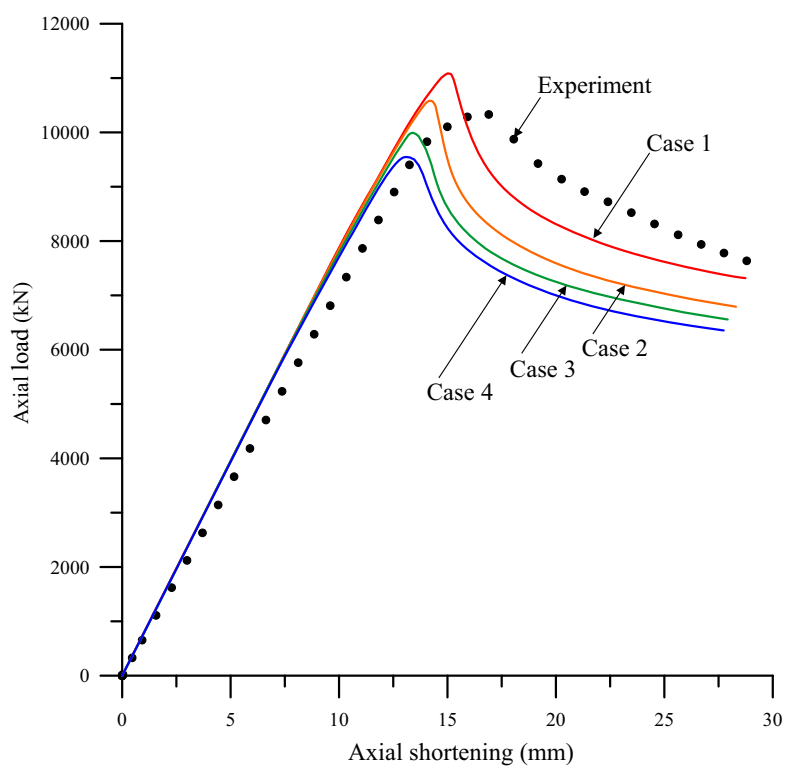

(a) Axial load-axial shortening curve

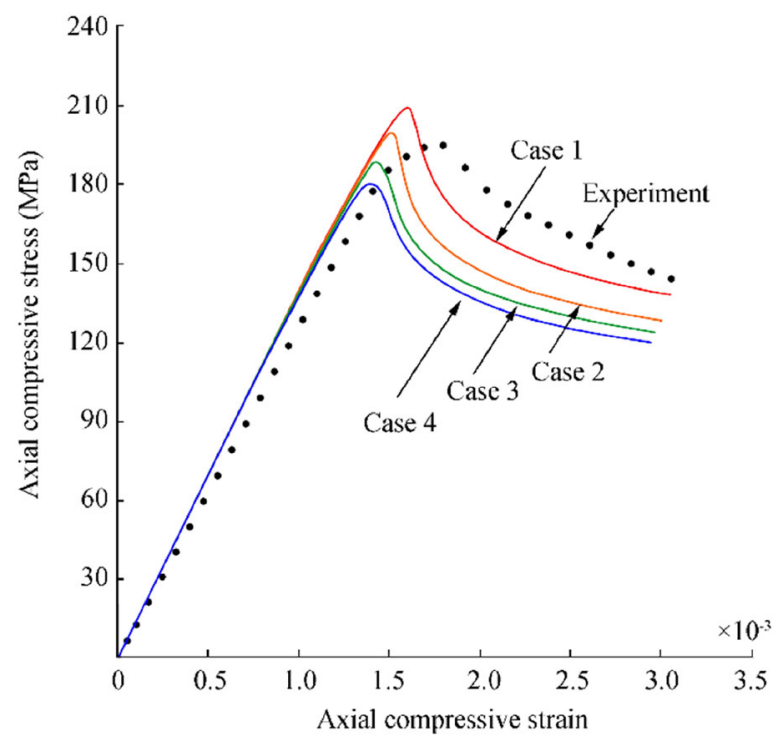

(b) Axial compressive stress-axial compressive strain curve

Figure 23 The ultimate compressive strength behavior of the plate panel obtained from the ANSYS finite element method analysis

5) The ALPS/ULSAP predictions showed that the plate panels of the four cases all reached the ultimate limit state triggered by tripping of the longitudinal stiffeners. This corresponds to the panel collapse mode of case 1 by the experiment.

6. The ALPS/ULSAP and ALPS/SPINE solutions show a similar trend to the ANSYS finite element method computations, but the reduction rate of the ultimate compressive strength is much smaller.

7. It is concluded that the average thickness for plate panels with nonuniform thickness can approximately be used as

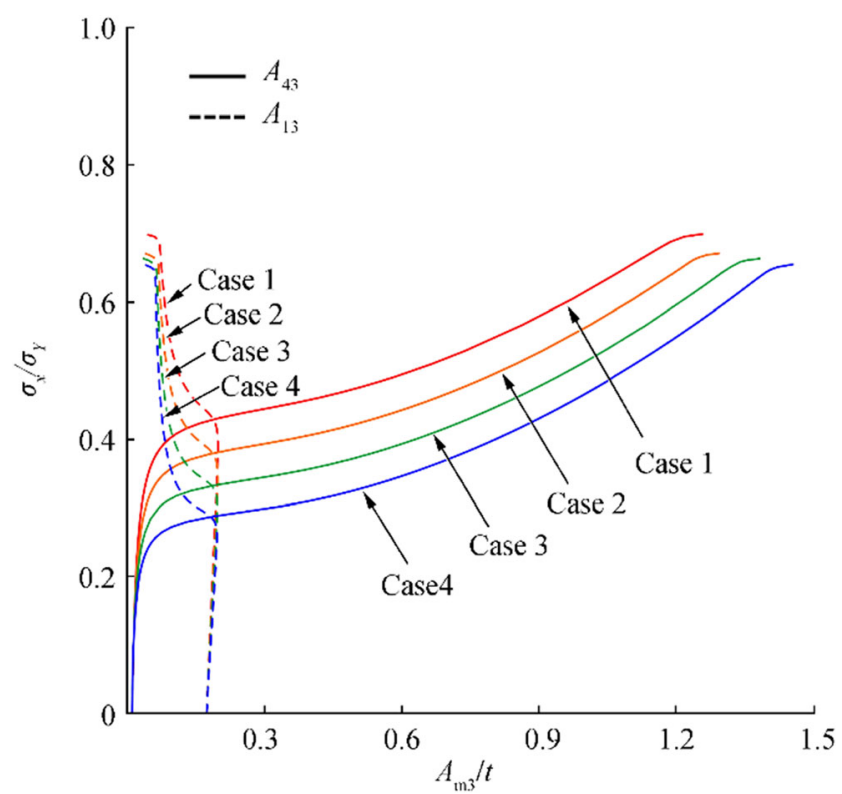

Figure 24 The ALPS/SPINE ultimate compressive strength behavior of the plate panel in terms of the added deflection components

a representative for the ultimate compressive strength analysis by analytical methods which model the plate panels with uniform thickness.

Open Access This article is licensed under a Creative Commons Attribution 4.0 International License, which permits use, sharing, adaptation, distribution and reproduction in any medium or format, as long as you give appropriate credit to the original author(s) and the source, provide a link to the Creative Commons licence, and indicate if changes were made. The images or other third party material in this article are included in the article's Creative Commons licence, unless indicated otherwise in a credit line to the material. If material is not included in the article's Creative Commons licence and your intended use is not permitted by statutory regulation or exceeds the permitted use, you will need to obtain permission directly from the copyright holder. To view a copy of this licence, visit http://creativecommons.org/licenses/by/4.0/.

Table 5 Comparison of the ultimate compressive strength of the plate panels between the three method predictions together with the experiment (unit: $\mathrm{MPa}$ )

\begin{tabular}{cccll}
\hline Case & Experiment & ANSYS $^{1}$ & $\begin{array}{l}\text { ALPS/ } \\
\text { ULSAP }^{2}\end{array}$ & $\begin{array}{l}\text { ALPS/ } \\
\text { SPINE }^{2}\end{array}$ \\
\hline 1 & 248.6 & 266.5 & 240.6 & 232.1 \\
2 & - & 254.4 & 237.5 & 222.7 \\
3 & - & 240.2 & 234.8 & 220.2 \\
4 & - & 229.5 & 232.7 & 217.4 \\
\hline
\end{tabular}

${ }^{1}$ Actual $t_{1}$ and $t_{2}$ were applied

${ }^{2} t_{\mathrm{eq}}=t_{2}$ (lower thickness) was applied 


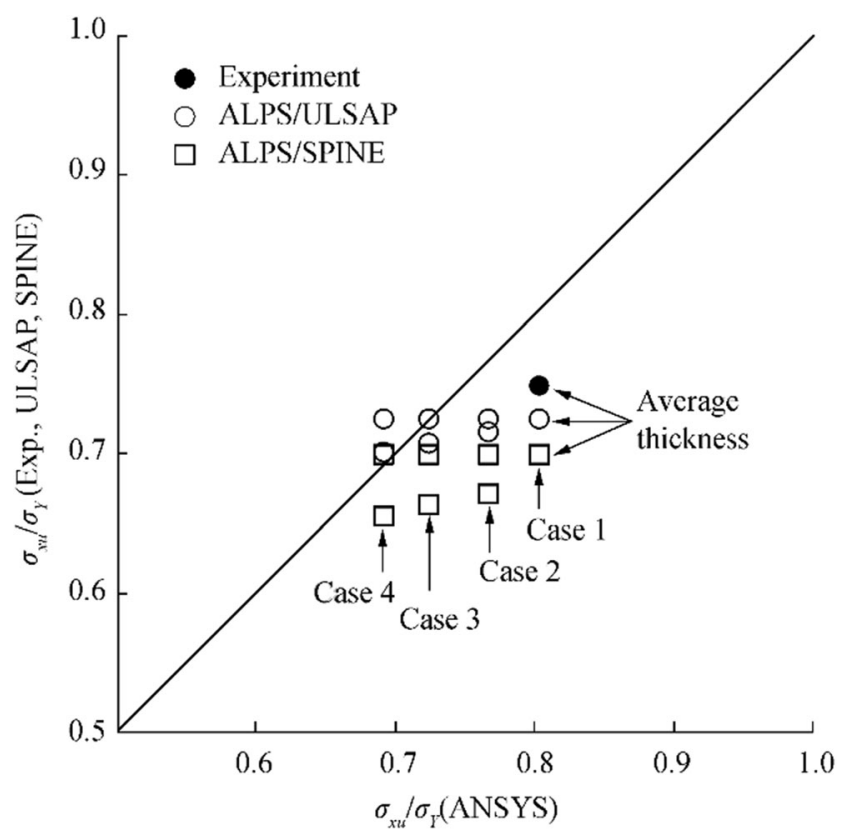

Figure 25 Comparison of the ultimate compressive strength between the analyses and the experiment for the plate panel with varying the thickness

\section{References}

Abdussamie N, Ojeda R, Daboos M (2018) ANFIS method for ultimate strength prediction of unstiffened plates with pitting corrosion. Ships and Offshore Structures 13(5):540-550

ALPS/SPINE (2020) Elastic-plastic large deflection analysis of plates and stiffened pan els under combined biaxial compression / tension, biaxial in-plane bending, edge shear and lateral pressure loads. MAESTRO Marine LLC, Greenboro https://www.maestromarine. com. Accessed on 3 Jan 2020

ALPS/ULSAP (2020) Ultimate strength analysis of plates and stiffened panels under combined biaxial compression / tension, edge shear and lateral loads. MAESTRO Marine LLC, Greenboro https:// www.maestromarine.com Accessed on 3 Jan 2020

ANSYS (2019) User's manual (version 10.0). ANSYS Inc., Canonsburg

ASTM (2011) ASTM E8/E8M-09 Standard test methods for tension testing of metallic materials. ASTM International, West Conshocken, PA

Benson S, Downes J, Dow RS (2011) Ultimate strength characteristics of aluminium plates for high-speed vessels. Ships and Offshore Structures 6(1-2):67-80

de Faria AR, de Almeida SFM (2003) Buckling optimization of plates with variable thickness subjected to nonuniform uncertain loads. Int J Solids Struct 40:3955-3966

DNVGL (2017) Rules for classification-ships, part 2 materials and welding, chapter 4 fabrication and testing. Høvik, Norway

Fletcher CAJ (1984) Computational Galerkin method. Springer-Verlag, New York

Gannon L, Liu Y, Pegg N, Smith MJ (2013) Effect of three-dimensional welding-induced residual stress and distortion fields on strength and behaviour of flat-bar stiffened panels. Ships and Offshore Structures $8(5): 565-578$
Gannon L, Liu Y, Pegg N, Smith MJ (2016) Nonlinear collapse analysis of stiffened plates considering welding-induced residual stress and distorion. Ships and Offshore Structures 11(3):228-244

Iijima K, Suzaki Y, Fujikubo M (2015) Scaled model tests for the postultimate strength collapse behaviour of a ship's hull girder under whipping loads. Ships Offshore Struct 10(1):31-38

Jagite G, Bigot F, Derbanne Q, Malenica S, Le Sourne H, de Lauzon J, Cartraud P (2019) Numerical investigation on dynamic ultimate strength of stiffened panels considering real loading scenarios. Ships and Offshore Structures 14(suppl):374-386

Jagite G, Bigot F, Derbanne Q, Malenica S, Le Sourne H, Cartraud P (2020) A parametric study on the dynamic ultimate strength of a stiffened panel subjected to wave- and whipping-induced stresses. Ships and Offshore Structures:1-15. https://doi.org/10.1080/ 17445302.2020.1790985

Khan I, Zhang S (2011) Effects of welding-induced residual stress on ultimate strength of plates and stiffened panels. Ships and Offshore Structures 6(4):297-309

Khedmati MR, Pedram M, Rigo P (2014) The effects of geometrical imperfections on the ultimate strength of aluminium stiffened plates subject to combined uniaxial compression and lateral pressure. Ships and Offshore Structures 9(1):88-109

Khedmati MR, Memarian HR, Fadavie M, Zareel MR (2016) Empirical formulations for estimation of ultimate strength of continuous aluminium stiffened plates under combined transverse compression and lateral pressure. Ships and Offshore Structures 11(3):258-277

Kim UN, Choe IH, Paik JK (2009) Buckling and ultimate strength of perforated plate panels subject to axial compression: experimental and numerical investigations with design formulations. Ships and Offshore Structures 4(4):337-361

Kim DK, Kim SJ, Kim HB, Zhang XM, Li CG, Paik JK (2015) Ultimate strength performance of bulk carriers with various corrosion additions. Ships and Offshore Structures 10(1):59-78

Kumar MS, Alagusundaramoorthy P, Sundaravadivelu R (2009) Interaction curves for stiffened panel with circular opening under axial and lateral loads. Ships and Offshore Structures 4(2):133-143

Lee DH, Paik JK (2020) Ultimate strength characterfistics of as-built ultra-large containership hull structures under combined vertical bending and torsion. Ships and Offshore Structures:1-18. https:// doi.org/10.1080/17445302.2020.1747829

Lee DH, Kim SJ, Lee MS, Paik JK (2019) Ultimate limit state based design versus allowable working stress based design for box girder crane structures. Thin-Walled Struct 134:491-507

Le-Manh T, Huynh-Van Q, Phan TD, Phand HD, Nguyen-Xuan H (2017) Isogeometric nonlinear bending and buckling analysis of variable-thickness composite plate structures. Compos Struct 159: 818-826

Magoga T, Flockhart C (2014) Effect of weld-induced imperfections on the ultimate strength of an aluminium patrol boat determined by the ISFEM rapid assessment method. Ships and Offshore Structures 9(2):218-235

Ozguc O, Das PK, Barltrop N (2006) A proposed method to evaluate hull girder ultimate strength. Ships and Offshore Structures 1(4):335345

Paik JK (2007) Ultimate strength of steel plates with a single circular hole under axial compressive loading along short edges. Ships and Offshore Structures 2(4):355-360

Paik JK (2018) Ultimate limit state analysis and design of plated structures. John Wiley \& Sons, Chichester

Paik JK (2020) Advanced structural safety studies with extreme conditions and accidents. Springer, Singapore

Paik JK, Lee MS (2005) A semi-analytical method for the elastic-plastic large deflection analysis of stiffened panels under combined biaxial 
compression/tension, biaxial in-plane bending, edge shear and lateral pressure loads. Thin-Walled Struct 43(2):375-410

Paik JK, Thayamballi AK, Lee SK, Kang SJ (2001) A semi-analytical method for the elastic-plastic large deflection analysis of welded steel or aluminum plating under combined in-plane and lateral pressure loads. Thin-Walled Struct 39:125-152

Paik JK, Kim DK, Park DH, Kim HB, Mansour AE, Caldwell JB (2013) Modified Paik-Mansour formular for ultimate strength calculations of ship hulls. Ships and Offshore Structures 8(3-4):245-260

Paik JK, Lee DH, Noh SH, Park DK, Ringsberg JW (2020a) Full-scale collapse testing of a steel stiffened plate structure under cyclic axialcompressive loading. Structures 26:996-1009

Paik JK, Lee DH, Noh SH, Park DK, Ringsberg JW (2020b) Full-scale collapse testing of a steel stiffened plate structure under axialcompressive loads triggered by brittle fracture at cryogenic condition. Ships and Offshore Structures.:1-17. https://doi.org/10.1080/ 17445302.2020.1787930

Paik JK, Lee DH, Noh SH, Park DK, Ringsberg JW (2020c) Full-scale collapse testing of a steel stiffened plate structure under axialcompressive loads at temperature of $-80^{\circ} \mathrm{C}$. Ships and Offshore Structures.:1-16. https://doi.org/10.1080/17445302.2020.1791685

Paik JK, Ryu MG, He K, Lee DH, Lee SY, Park DK, Thomas G (2020d) Full-scale fire testing to collapse of steel stiffened plate structures under lateral patch loading (part 1)—without passive fire protection. Ships and Offshore Structures.:1-16. https://doi.org/10.1080/ 17445302.2020 .1764705

Paik JK, Ryu MG, He K, Lee DH, Lee SY, Park DK, Thomas G (2020e) Full-scale fire testing to collapse of steel stiffened plate structures under lateral patch loading (part 2) - with passive fire protection. Ships and Offshore Structures.:1-12. https://doi.org/10.1080/ 17445302.2020.1764706

Rahbar-Ranji A, Zarookoan A (2015) Ultimate stregth of stiffened plates with a transverse crack under uniaxial compression. Ships and Offshore Structures 10(4):416-425
Ringsberg JW, Li Z, Johnson E, Kuznecovs A, Shafieisabet R (2018) Reduction in ultimate strength capacity of corroded ships involved in collision accidents. Ships and Offshore Structures 13(sup1):155166

Shi G, Gao D (2020) Ultimate strength of U-type stiffened panels for hatch covers used in ship cargo holds. Ships and Offshore Structures:1-12. https://doi.org/10.1080/17445302.2020.1724359

Shi G, Wang D (2012) Ultimate strength model experiment regarding a container ship's hull structures. Ships and Offshore Structures 7(2): $165-184$

Tash FY, Neya BN (2020) An analytical solution for bending of transversely isotropic thick rectangular plates with variable thickness. Appl Math Model 77:1582-1602

Wang G, Sun H, Peng H, Uemori R (2009) Buckling and ultimate strength of plates with openings. Ships and Offshore Structures $4(1): 43-53$

Yi MS, Lee DH, Lee HH, Paik JK (2020a) Direct measurements and numerical predictions of welding-induced initial deformations in a full-scale steel stiffened plate structure. Thin-Walled Struct 153: 106786. https://doi.org/10.1016/j.tws.2020.106786

Yi MS, Noh SH, Lee DH, Seo DH, Paik JK (2020b) Direct measurements, numerical predictions and simple formula estimations of welding-induced biaxial residual stresses in a full-scale steel stiffened plate structure. Structures. https://doi.org/10.1016/j.istruc. 2020.05.030

Zenkour AM (2003) An exact solution for the bending of thin rectangular plates with uniform, linear, and quadratic thickness variations. Int $\mathrm{J}$ Mech Sci 45:295-315

Zhang S (2016) A review and study on ultimate strength of steel plates and stiffened panels in axial compression. Ships and Offshore Structures 11(1):81-91

Zhang J, Hua Z, Tang W, Wang F, Wang S (2018) Buckling of externally pressurised egg-shaped shells with variable and constant wall thickness. Thin-Walled Struct 132:111-119 